\title{
Mitochondrial Genomes Provide Insights into the Phylogeny of Lauxanioidea (Diptera: Cyclorrhapha)
}

\author{
Xuankun Li ${ }^{1,+}$, Wenliang Li ${ }^{2,+}$, Shuangmei Ding ${ }^{1}$, Stephen L. Cameron ${ }^{3}$, Meng Mao ${ }^{4}$, Li Shi ${ }^{5, *}$ \\ and Ding Yang ${ }^{1, *}$ \\ 1 Department of Entomology, China Agricultural University, Beijing 100193, China; \\ xuankun.li@csiro.au (X.L.); shuangmeiding@cau.edu.an (S.D.) \\ 2 College of Forestry, Henan University of Science and Technology, Luoyang 471023, China; \\ wenliangli@haust.edu.cn \\ 3 Department of Entomology, Purdue University, West Lafayette, IN 47907, USA; cameros@purdue.edu \\ 4 Department of Plant and Environmental Protection Science, University of Hawaii at Manoa, \\ Honolulu, HI 96822, USA; mm663@uowmail.edu.au \\ 5 College of Agronomy, Inner Mongolia Agricultural University, Hohhot 010018, China \\ * Correspondences: lirui2003@imau.edu.cn (L.S.); dingyang@cau.edu.cn (D.Y.); \\ Tel.: +86-471-431-7421 (L.S.); +86-10-6273-2999 (D.Y.) \\ + These authors contributed equally to this work.
}

Academic Editor: Kun Yan Zhu

Received: 26 January 2017; Accepted: 1 April 2017; Published: 14 April 2017

\begin{abstract}
The superfamily Lauxanioidea is a significant dipteran clade including over 2500 known species in three families: Lauxaniidae, Celyphidae and Chamaemyiidae. We sequenced the first five (three complete and two partial) lauxanioid mitochondrial $(\mathrm{mt})$ genomes, and used them to reconstruct the phylogeny of this group. The lauxanioid $\mathrm{mt}$ genomes are typical of the Diptera, containing all 37 genes usually present in bilaterian animals. A total of three conserved intergenic sequences have been reported across the Cyclorrhapha. The inferred secondary structure of 22 tRNAs suggested five substitution patterns among the Cyclorrhapha. The control region in the Lauxanioidea has apparently evolved very fast, but four conserved structural elements were detected in all three complete $\mathrm{mt}$ genome sequences. Phylogenetic relationships based on the mt genome data were inferred by Maximum Likelihood and Bayesian methods. The traditional relationships between families within the Lauxanioidea, (Chamaemyiidae + (Lauxaniidae + Celyphidae)), were corroborated; however, the higher-level relationships between cyclorrhaphan superfamilies are mostly poorly supported.
\end{abstract}

Keywords: Lauxanioidea; Cyclorrhapha; mitochondrial genome; phylogeny; RNAs; intergenic sequences

\section{Introduction}

The mitochondrion (mt), one of the fundamental eukaryotic organelles, is descended from an $\alpha$-proteobacterium and as such retains a remnant, bacterial-like genome [1-3]. The mt genome has been widely used as an estimator for phylogentic studies, mainly because: (1) the high copy number and commonly available conserved primer sets make them easy to obtain [4]; and (2) they have enough phylogenetic information for inference over extensive taxonomic scales (e.g., [5-9]). Since the first insect mt genome was published by Clary and Wolstenholme in 1985 [10], the number of sequenced insect $\mathrm{mt}$ genomes has risen rapidly and $\mathrm{mt}$ genomes are available from every insect order [2]. The Diptera (flies) are one of the most extensively sequenced orders amongst the Insecta, with 115 complete, nearly-complete or partial mt genomes in GenBank (as of 1 July 2015) (Table 1). Note, here we define 
nearly-complete genomes as those for which none or only part of the control region has been sequenced; partial genomes are those with all 13 PCGs (protein-encoding genes) sequenced but for which one or more tRNA or rRNA genes remain unsequenced. Mt genomes with none of the 13 PCGs completely sequenced were excluded from the above statistics and the following comparative analyses.

Table 1. Summary of mitochondrion (mt) genome sequences from Brachycera and three outgroups.

\begin{tabular}{|c|c|c|c|c|}
\hline Family & Species & Published Information & Code & Length (bp) \\
\hline Tipulidae & Tipula abdominalis \# & [11] & JN_861743 & - \\
\hline Chironomidae & Chironomus tepperi ${ }^{\#}$ & [11] & NC_016167 & 15,652 \\
\hline Tanyderidae & Protoplasa fitchii \# & [11] & NC_016202 & 16,154 \\
\hline Nemestrinidae & Trichophthalma punctate * & [12] & NC_008755 & 16,396 \\
\hline Tabanidae & Cydistomyia duplonotata * & [12] & NC_008756 & 16,247 \\
\hline Phoridae & Megaselia scalaris* & [13] & NC_023794 & 15,599 \\
\hline Syrphidae & Simosyrphus grandicornis * & [12] & NC_008754 & 16,141 \\
\hline Fergusoninidae & Fergusonina taylori* & [14] & NC_016865 & 16,000 \\
\hline Agromyzidae & $\begin{array}{l}\text { Liriomyza bryoniae* } \\
\text { Liriomyza huidobrensis } \\
\text { Liriomyza sativae * } \\
\text { Liriomyza trifolii }\end{array}$ & $\begin{array}{l}{[15]} \\
{[15]} \\
{[16]} \\
{[17]}\end{array}$ & $\begin{array}{l}\text { NC_016713 } \\
\text { NC_016716 } \\
\text { NC_015926 } \\
\text { NC_014283 }\end{array}$ & $\begin{array}{l}16,183 \\
16,236 \\
15,551 \\
16,141\end{array}$ \\
\hline Tephritidae & $\begin{array}{l}\text { Bactrocera carambolae } \\
\text { Bactrocera correcta } \\
\text { Bactrocera cucurbitae * } \\
\text { Bactrocera dorsalis } \\
\text { Bactrocera minax } \\
\text { Bactrocera oleae } \\
\text { Bactrocera papayae } \\
\text { Bactrocera philippinensis } \\
\text { Bactrocera tryoni } \\
\text { Ceratitis capitata } \\
\text { Procecidochares utilis }\end{array}$ & $\begin{array}{c}{[18]} \\
\text { Wu et al. Unpublished } \\
\text { Wu et al. Unpublished } \\
{[19]} \\
{[20]} \\
{[21]} \\
{[18]} \\
{[18]} \\
{[22]} \\
{[23]} \\
\text { Wu et al. Unpublished }\end{array}$ & $\begin{array}{l}\text { NC_009772 } \\
\text { NC_018787 } \\
\text { NC_016056 } \\
\text { NC_008748 } \\
\text { NC_014402 } \\
\text { NC_005333 } \\
\text { NC_009770 } \\
\text { NC_009771 } \\
\text { NC_014611 } \\
\text { NC_000857 } \\
\text { NC_020463 }\end{array}$ & $\begin{array}{l}15,915 \\
15,936 \\
15,825 \\
15,915 \\
16,043 \\
15,815 \\
15,915 \\
15,915 \\
15,925 \\
15,980 \\
15,922\end{array}$ \\
\hline Drosophilidae & $\begin{array}{l}\text { Drosophila ananassae } \\
\text { Drosophila erecta } \\
\text { Drosophila grimshawi } \\
\text { Drosophila littoralis } \\
\text { Drosophila melanogaster * } \\
\text { Drosophila mojavensis } \\
\text { Drosophila persimilis } \\
\text { Drosophila pseudoobscura } \\
\text { Drosophila santomea * } \\
\text { Drosophila sechellia } \\
\text { Drosophila simulans } \\
\text { Drosophila virilis } \\
\text { Drosophila willistoni } \\
\text { Drosophila yakuba * }\end{array}$ & $\begin{array}{l}{[24]} \\
{[24]} \\
{[24]} \\
{[25]} \\
{[26]} \\
{[24]} \\
{[24]} \\
{[27]} \\
{[28]} \\
{[29]} \\
{[29]} \\
{[24]} \\
{[24]} \\
{[10]}\end{array}$ & $\begin{array}{c}\text { BK006336 (Without CR) } \\
\text { BK006335 (Without CR) } \\
\text { BK006341 (Without CR) } \\
\text { NC_011596 } \\
\text { NC_001709 } \\
\text { BK006339 (Without CR) } \\
\text { BK006337 (Without CR) } \\
\text { NC_018348 (Without CR) } \\
\text { NC_023825 } \\
\text { NC_005780 (Without CR) } \\
\text { NC_005781 (Without CR) } \\
\text { BK006340 (Without CR) } \\
\text { BK006338 (Without CR) } \\
\text { NC_001322 }\end{array}$ & $\begin{array}{c}- \\
- \\
- \\
16,017 \\
19,517 \\
- \\
- \\
- \\
16,022 \\
- \\
- \\
- \\
- \\
16,019\end{array}$ \\
\hline Sepsidae & Nemopoda mamaevi* & {$[30]$} & KM605250 & 15,878 \\
\hline Lauxaniidae & $\begin{array}{c}\text { Cestrotus liui }{ }^{*} \\
\text { Pachycerina decemlineata * }\end{array}$ & $\begin{array}{l}\text { Present study } \\
\text { Present study }\end{array}$ & $\begin{array}{l}\text { KX372559 } \\
\text { KX372561 }\end{array}$ & $\begin{array}{l}16,171 \\
16,286\end{array}$ \\
\hline Chamaemyiidae & Chamaemyia juncorum * & Present study & KX372560 & - \\
\hline Celyphidae & $\begin{array}{c}\text { Celyphus obtectus * } \\
\text { Spanicelyphus pilosus * }\end{array}$ & $\begin{array}{l}\text { Present study } \\
\text { Present study }\end{array}$ & $\begin{array}{l}\text { KX372558 } \\
\text { KX372562 }\end{array}$ & $\begin{array}{c}- \\
16,426\end{array}$ \\
\hline Muscidae & $\begin{array}{l}\text { Haematobia irritans } \\
\text { Musca domestica * } \\
\text { Stomoxys calcitrans }\end{array}$ & $\begin{array}{l}31] \\
{[32]} \\
{[31]} \\
\end{array}$ & $\begin{array}{c}\text { NC_007102 } \\
\text { NC_024855 } \\
\text { DQ533708 }\end{array}$ & $\begin{array}{l}16,078 \\
16,108 \\
15,790\end{array}$ \\
\hline Anthomyiidae & Delia platura & [33] & KР01268 & - \\
\hline Fanniidae & Euryomma sp. & [33] & KР01269 & - \\
\hline Scathophagidae & Scathophaga stercoraria * & [32] & NC_024856 & 16,223 \\
\hline
\end{tabular}


Table 1. Cont.

\begin{tabular}{|c|c|c|c|c|}
\hline Family & Species & Published Information & Code & Length (bp) \\
\hline \multirow{13}{*}{ Calliphoridae } & Calliphora vicina & [6] & NC_019639 & 16,112 \\
\hline & Chrysomya albiceps & [6] & NC_019631 & 15,491 \\
\hline & Chrysomya bezziana & [6] & NC_019632 & 15,236 \\
\hline & Chrysomya megacephala & {$[6]$} & NC_019633 & 15,273 \\
\hline & Chrysomya putoria * & [34] & NC_002697 & 15,837 \\
\hline & Chrysomya rufifacies & [6] & NC_019634 & 15,412 \\
\hline & Chrysomya saffranea & [6] & NC_019635 & 15,839 \\
\hline & Protophormia terraenovae & {$[6]$} & NC_019636 & 15,170 \\
\hline & Cochliomyia hominivorax & [35] & NC_002660 & 16,022 \\
\hline & Lucilia cuprina & [6] & NC_019573 & 15,952 \\
\hline & Lucilia porphyrina & [6] & NC_019637 & 15,877 \\
\hline & Lucilia sericata & [6] & NC_009733 & 15,945 \\
\hline & Hemipyrellia ligurriens & [6] & NC_019638 & 15,938 \\
\hline Polleniidae & Pollenia rudis & [6] & JX913761 (Partial Genome) & - \\
\hline \multirow{2}{*}{ Oestridae } & Dermatobia hominis & [36] & NC_006378 & 16,460 \\
\hline & Hypoderma lineatum * & [37] & NC_013932 & 16,354 \\
\hline \multirow{2}{*}{ Sarcophagidae } & Sarcophaga impatiens * & [6] & NC_017605 & 15,169 \\
\hline & Sarcophaga peregrina & [38] & NC_023532 & 14,922 \\
\hline \multirow{3}{*}{ Tachinidae } & Elodia flavipalpis * & [7] & NC_018118 & 14,932 \\
\hline & Exorista sorbillans & [39] & NC_014704 & 14,960 \\
\hline & Rutilia goerlingiana & {$[6]$} & NC_019640 & 15,331 \\
\hline
\end{tabular}

"-" not available (unknown or incomplete data); “*” species used in phylogenetic analysis; "\#\#" outgroup.

The dipteran superfamily Lauxanioidea was first proposed by Hendel $[40,41]$ and includes three families: Lauxaniidae, Celyphidae and Chamaemyiidae. Two additional families, Periscelididae and Eurychoromyiidae, were added into this group by Hennig [42], but he later excluded the Periscelididae [43] and placed the Eurychoromyiidae into the Sciomyzoidea [44]. The Eurychoromyiidae was recently combined into the Lauxaniidae [45], and therefore the superfamily is still composed of the three original families proposed by Hendel $[40,41]$. The Lauxaniidae, including 172 genera and 2150 known species, is one of the most diverse families of acalyptrate flies, and occurs on all continents except for Antarctica. As they are sensitive to pesticides and fungicides, lauxaniid flies have been used to evaluate environmental change in field ecosystems [46]. The Celyphidae, commonly known as beetle flies, are one of the most easily recognized fly families with a shiny, enlarged, elytra-like scutellum that covers most of the abdomen. It is a relatively small family with about 120 known species, and mostly occurs in the Oriental bioregion. Larvae of most Lauxaniidae and Celyphidae species have similar habits, feeding on decaying leaves or grass, while some Lauxaniidae species occur only in birds' nests [47]. The Chamaemyiidae, on the other hand, have a very different habit from the above two families-all known larvae feed on aphids and scale insects. There are around 350 known species of Chamaemyiidae worldwide, but they are infrequently collected [47]. Because of their importance as predators of aphids, they are also called "aphid files." Some species are even used as natural enemies in biological control measures. Currently, no mt genomes have been reported from any members of this superfamily.

The major synapomorphies for the group are convergent post-ocellar bristles, an abbreviated anal vein, and that the male abdominal tergites 7 and 8 are fused [48]. All early major classifications $[41,43,49,50]$ as well as the recent major phylogenetic synthesis of flies [51] supported the monophyly of the Lauxanioidea. However, the phylogeny of this group has been the subject of a long-lasting, contentious debate. Hennig [52] proposed that the sister group of the Lauxanioidea was probably the Sciomyzoidea. Griffiths [50], however, concluded that the Lauxanioidea and Sciomyzoidea were only remotely related, and suggested that the Schizophora include the Lonchaeoidea, Lauxanioidea, Drosophiloidea and Nothyboidea. McAlpine [49] resolved the phylogenetic arrangement of the Acalyptratae, which supported Hennig [52] in finding that 
the Lauxanioidea and Sciomyzoidea were sister groups. This solution was also supported by the supertree analysis of Yeates et al. [48]. Weigmann et al. [51] suggested a sister relationship between the clades (Tephritidae + Sepsidae) and (Diopsidae + Lauxaniidae). Conversely, morphological data weakly supported the clade (Lauxaniidae + (Agromyzidae + (Chloropidae + (Drosophilidae + Sphaeroceridae)))) [53]. The aim of this current study was to test the monophyly and intraordinal placement of the Lauxanioidea using mitochondrial genome data, a data source that has proven valuable in resolving relationships between fly families in many previous studies (e.g., [30,31]).

\section{Results and Discussion}

\subsection{General Features of Mitochondrial Genome Organization}

In this study, the mt genomes of five lauxanioid flies, including two complete mt genomes of the Lauxaniidae, one complete and one partial $\mathrm{mt}$ genome of the Celyphidae and one partial $\mathrm{mt}$ genome of the Chamaemyidae, were sequenced for the first time (Figure 1). The sequenced mt genomes are typically circular, double-stranded molecules, containing the 37 genes (13 PCGs, 22 tRNA genes, and two rRNA genes) and a large control region (in arthropods, also known as A + T-rich region), which are usually present in bilaterian animals [2]. The length of the three complete mt genomes are 16,171 bp in Cestrotus liui, 16,286 bp in Pachycerina decemlineata and 16,426 bp in Spanicelyphus pilosus. They are medium-sized when compared with the mt genomes of other Cyclorrhapha, which range from 14,903 bp (Aldrichina grahami, Calliphoridae) [54] to 19,517 bp (Drosophila melanogaster, Drosophilidae) [26]. Within cyclorrhaphan $\mathrm{mt}$ genomes, length variation is limited in the PCGs, tRNA, and rRNA genes, but there is remarkable variation in the size of the control region (Figure 2). Mitochondrial gene pattern is the same as all previously published cyclorrhaphan $\mathrm{mt}$ genomes, as well as that of the inferred ancestral insect mt genome order. Majority strand (J-strand) includes 23 genes, while the remaining 14 genes are located on the minority strand ( $\mathrm{N}$-strand) encodes.
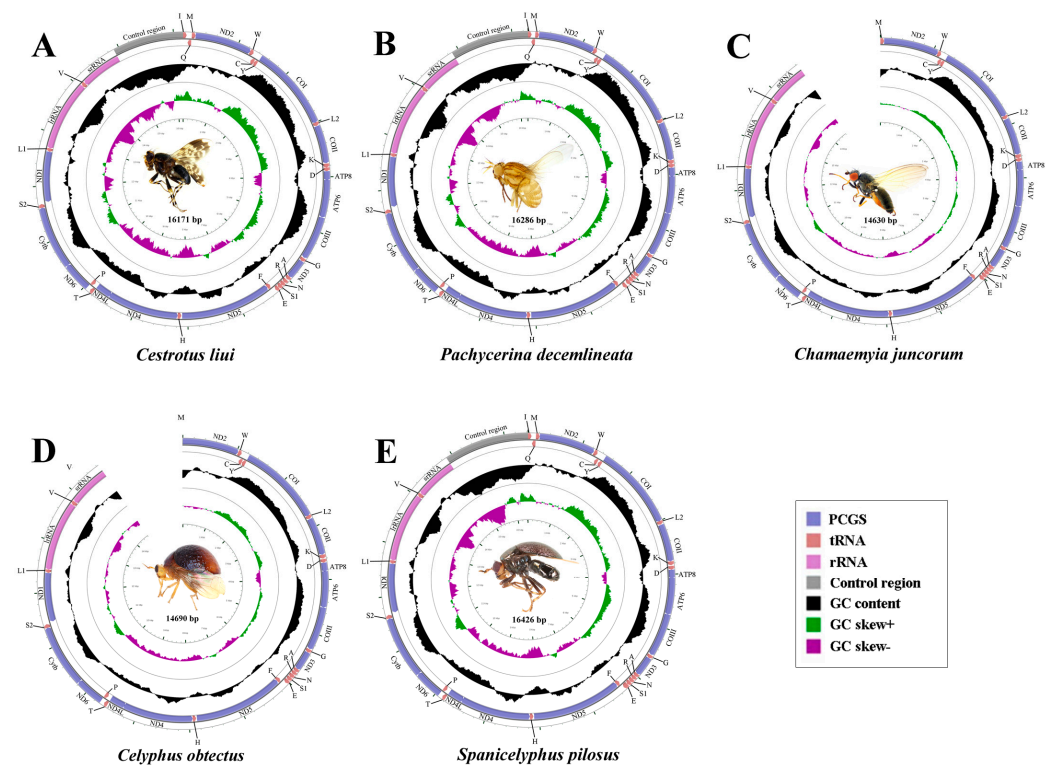

Figure 1. Mitochondrial genomes of five lauxaniid flies sequenced in this study. (A) Cestrotus liui; (B) Pachycerina decemlineata; (C) Chamaemyia juncorum; (D) Celyphus obtectus; (E) Spanicelyphus pilosus. Circular maps were drawn with CGView [55]. Arrows indicated the orientation of gene transcription. The tRNAs are denoted by the color blocks and are labelled according to the IUPAC-IUB single-letter amino acid codes (L1: CUN; L2: UUR; S1: AGN; S2: UCN). The guanine-cytosine (GC) content was plotted using a black sliding window, as the deviation from the average GC content of the entire sequence. GC-skew was plotted as the deviation from the average GC-skew of the entire sequence. The inner cycle indicated the location of genes in the $\mathrm{mt}$ genome. 


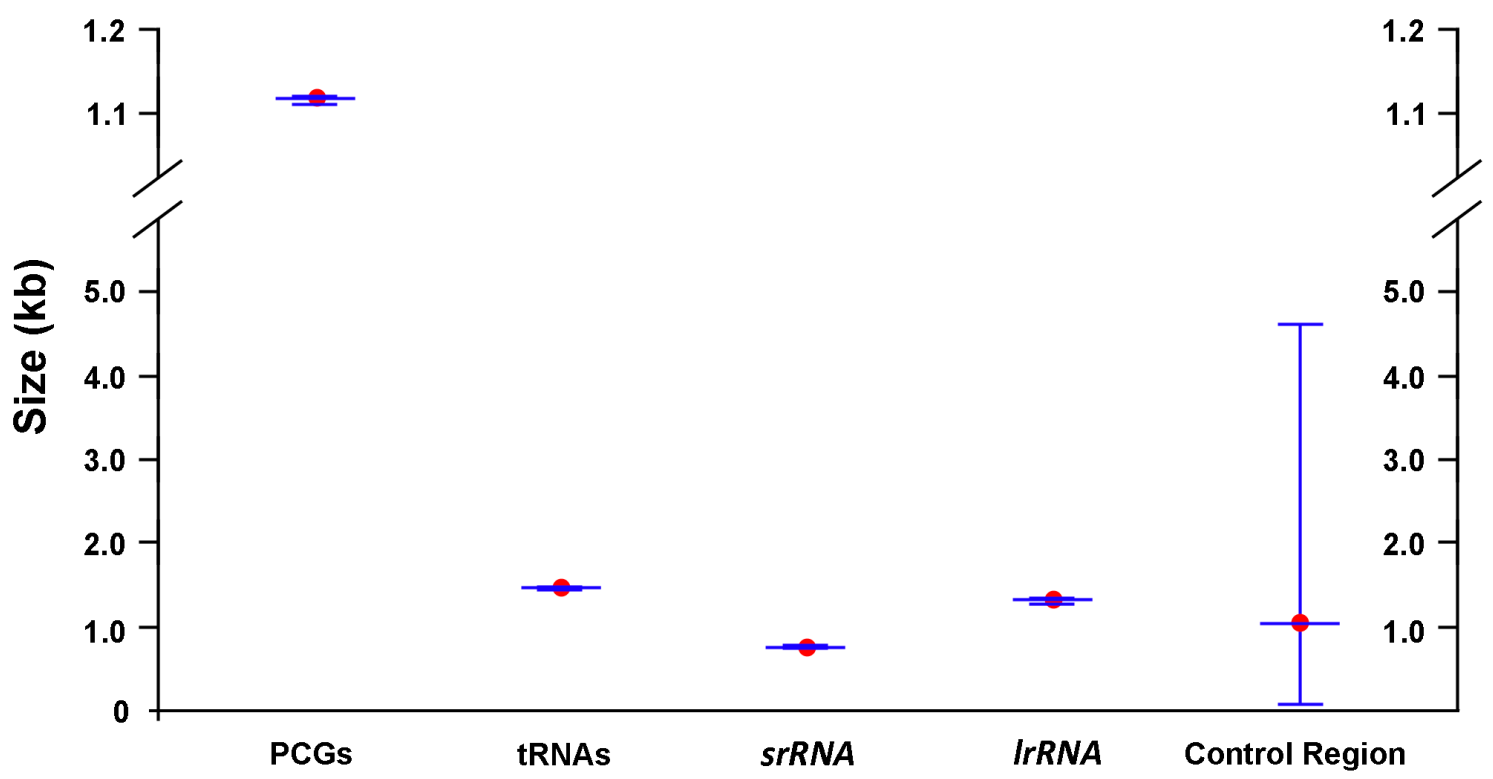

Figure 2. The size of protein-encoding genes (PCGs), tRNAs, srRNA, $\operatorname{lr} R N A$ and control region, respectively, among the sequenced Cyclorrhapha mt genomes.

\subsection{Base Composition}

The nucleotide composition of the three complete lauxanioid sequences was biased toward $\mathrm{A}$ and $\mathrm{T}$, with the overall $\mathrm{A}+\mathrm{T}$ content of the $\mathrm{mt}$ genomes ranging from $76.3 \%$ (in Pachycerina decemlineata, Lauxaniidae, present study) to $76.9 \%$ (in Spanicelyphus pilosus, Celyphidae, present study), with an intermediate value with respect to all reported cyclorrhaphan flies, which range from $67.2 \%$ (in Bactrocera minax, Tephritidae [20]) to $82.2 \%$ (in Drosophila melanogaster, Drosophilidae [26]). Most sequenced $\mathrm{mt}$ genomes of other cyclorrhaphan flies present a positive AT-skew for the J-strand with an average of 0.032 (except for in Stomoxys calcitrans (-0.001) [31] and in Simosyrphus grandicornis (-0.004) [12]), ranging from -0.004 (Simosyrphus grandicornis, Syrphidae [12]) to 0.131 (Bactrocera minax, Tephritidae [20]), whereas the AT-skew of the lauxanioid mt genomes were relatively low, ranging from -0.009 (Spanicelyphus pilosus, Celyphidae, present study) to 0.007 (Cestrotus liui, Lauxaniidae, present study). The average GC-skew of other cyclorrhaphan $\mathrm{mt}$ genomes was -0.190 , ranging from -0.315 (Bactrocera minax, Tephritidae [20]) to -0.124 (Haematobia irritans, Muscidae [31]), while the GC-skew of the lauxanioid mt genomes-which ranges from -0.159 (Cestrotus liui, Lauxaniidae, present study) to -0.174 (Spanicelyphus pilosus, Celyphidae, present study)—were average amongst reported cyclorrhaphan flies (Figure 3). In most metazoan mt genomes, the strand skew biases are found to be weakly positive AT-skew and strongly negative GC-skew for the J-strand. This pattern is consistent across most cyclorrhaphan $\mathrm{mt}$ genomes except in three species: Simosyrphus grandicornis (Syrphidae) [12], Spanicelyphus pilosus (Celyphidae, present study) and Stomoxys calcitrans (Muscidae) [31], which have negative AT-skew on the J-strand (Table S1). Three other insect families: Philopteridae (Phthiraptera), Aleyrodidae (Hemiptera) and Braconidae (Hymenoptera) were found with positive GC-skew and negative AT-skew on the J-strand [56], and a strongly positive AT-skew on the J-strand was detected in Isoptera [57]. In insects, gene direction, replication and codon positions are all related to the degree of AT-skew, whereas reversals in replication orientation affects the degree of GC-skew [56]. 


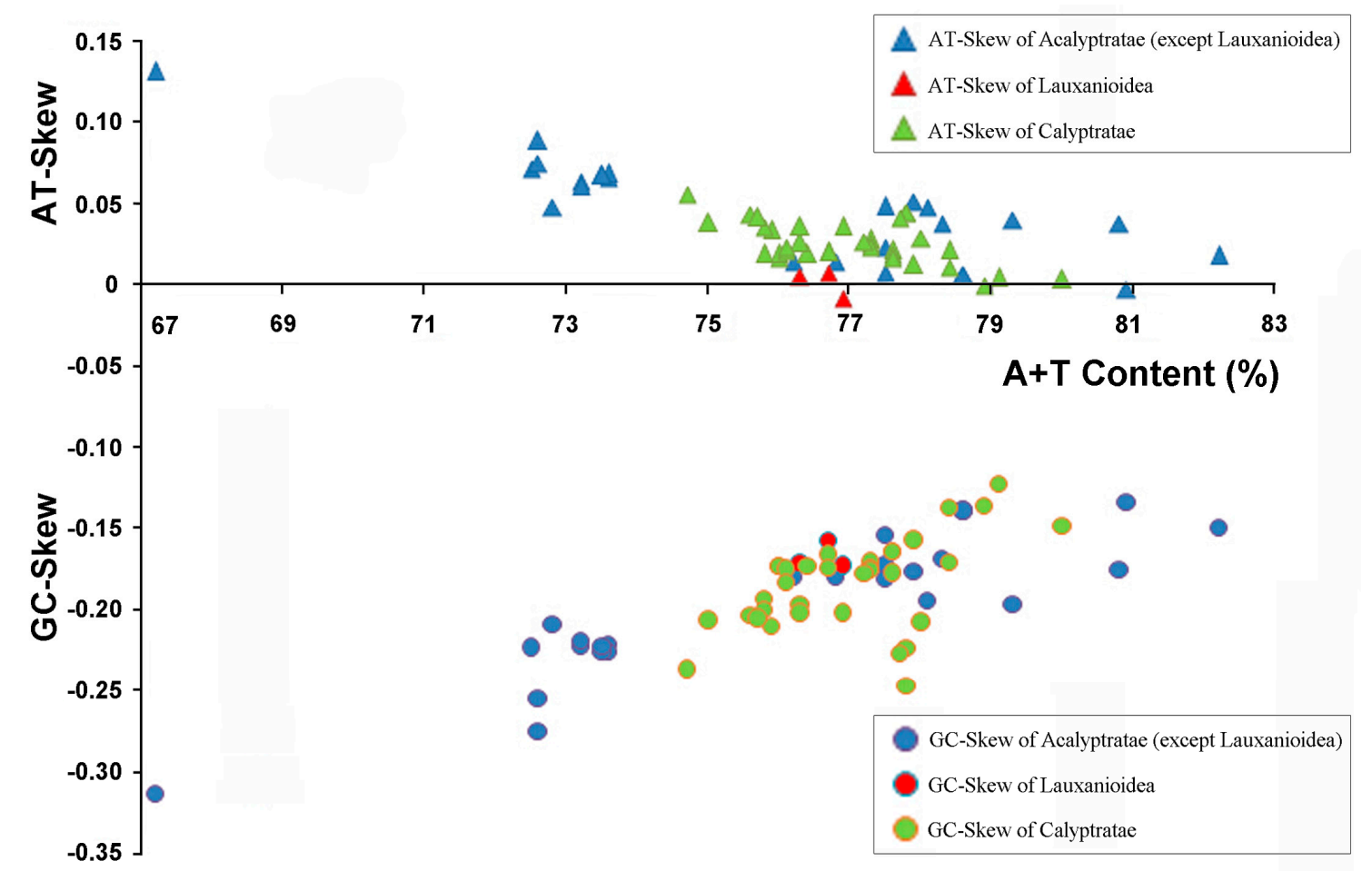

Figure 3. AT\% vs. AT-Skew and GC\% vs. AT-Skew in Cyclorrhapha mt genomes. Measured in bp percentage ( $X$-axis) and level of nucleotide skew ( $Y$-axis). Values are calculated on full length $\mathrm{mt}$ genomes. Blue, Acalyptratae (except Lauxanioidea); Red, Lauxanioidea; Green, Calyptratae; triangle, AT\% vs. AT-Skew; circle, GC \% vs. AT-Skew.

\subsection{Protein-Coding Genes and Codon Usage}

The overall $\mathrm{A}+\mathrm{T}$ content of the 13 PCGs in the five lauxanioid flies was between $74.3 \%$ (Pachycerina decemlineata and Celyphus obtectus) and 74.6\% (Cestrotus liui and Chamaemyia juncorum). The $\mathrm{A}+\mathrm{T}$ content of third codon positions $(89.1-90.2 \%)$ was much higher than either the first $(66.8-68.7 \%)$ or second codon positions (65.9-66.0\%) (Table S1). The AT-skew was strongly negative at the second codon positions (from -0.396 to -0.394 ), while it was weakly negative at the first and third codon positions (from -0.108 to -0.071 and from -0.042 to -0.022 , respectively), which results in a moderate negative AT-skew for the PCGs as a whole (from -0.166 to -0.147 ). On the other hand, the absence of significant CG-skew across the PCGs as a whole (from 0.000 to 0.031 ) masks strong skews at each codon position, as the strongly positive skew at the first codon position (from 0.227 to 0.253 ) is masked by strongly negative skews at the second and third codon positions (from -0.156 to -0.146 and from -0.208 to -0.038 , respectively) (Table S1).

All the PCGs in the five lauxanioid flies used canonical start codons. For all species, the ATP6, CO1, CO3, ND1, ND4 and ND4L genes started with ATG (Met), the ATP8, ND2, ND3, ND5 and ND6 genes started with ATT (Ile) (except Celyphus obtectus which used ATC (Ile) in ATP8, ND3 and ND5). Pachycerina decemlineata and Spanicelyphus pilosus used ATG (Met) in CO2, while for other species it started with TCG (Ser). For ND1, Cestrotus liui and Chamaemyia juncorum started with ATT (Ile), while the remaining species used TTG (Leu). TCG (Ser) has been identified as the most frequent start codon for $\mathrm{CO} 1$ in Cyclorrhapha [30], but ATG (Met) was used for CO1 in all five lauxanioid flies (Table S2).

The stop codons most commonly used in the five lauxanioid flies are TAA (ATP6, ATP8, CO2, CO3, ND2, ND4L and ND6) (the exception is Chamaemyia juncorum with an incomplete stop codon T in CO3) or TAG (CYTB, ND3) (the exception is Cestrotus liui with TAA in ND3). For all species, the incomplete stop codon T was used in CO1 (except Cestrotus liui and Chamaemyia juncorum which used 
TAA), ND1, ND4 (Cestrotus liui used TAA) and ND5 (Cestrotus liui used TAA, Pachycerina decemlineata used TAG) (Table S2).

$\mathrm{A}+\mathrm{T}$ bias is also reflected in the relative codon usage by the PCGs. The amino acid frequencies excluding stop codons are similar amongst the different lauxanioid mitochondrial genomes (Figure 4). The most frequently used codons across all species were TAA (Leu), AAT (Ile), AAA (Lys), TAT (Tyr), ATT (Asn), and ATA (Met). The only exception was Celyphus obtectus where the proportion of TCC (Gly) was slightly higher than ATA (Met). Three codons were apparently not used in the mitochondrial PCGs of the five lauxanioid flies. GCG (Arg) was absent from the PCGs of Celyphus obtectus, CAG (Leu) was not present in the PCGs of Cestrotus liui, Chamaemyia juncorum and Spanicelyphus pilosus, and CCT (Ser) was absent from the PCGs of Pachycerina decemlineata, Celyphus obtectus and Spanicelyphus pilosus (Figure 4).
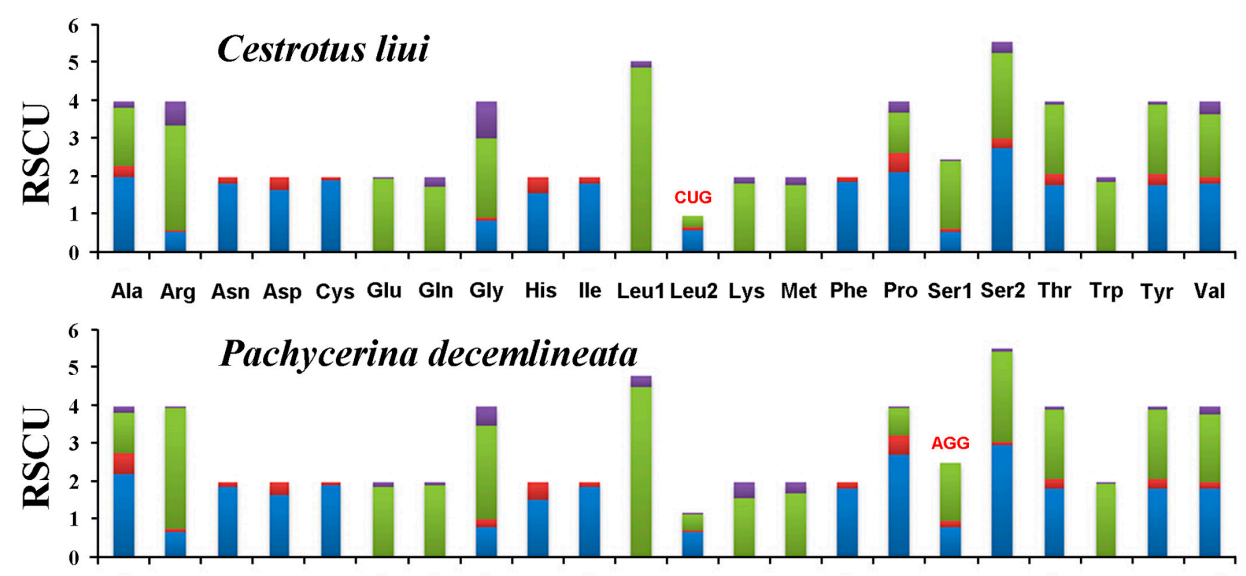

Ala Arg Asn Asp Cys Glu Gln Gly His lle Leu1 Leu2 Lys Met Phe Pro Ser1 Ser2 Thr Trp Tyr Val

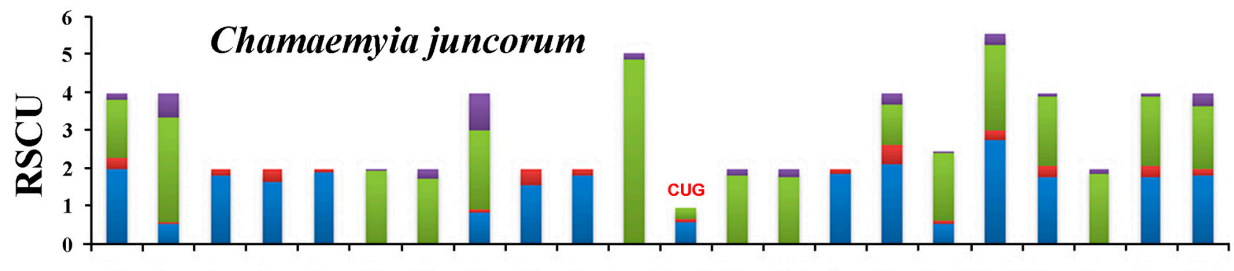

Ala Arg Asn Asp Cys Glu Gin Gly His lle Leu1 Leu2 Lys Met Phe Pro Ser1 Ser2 Thr Trp Tyr Val
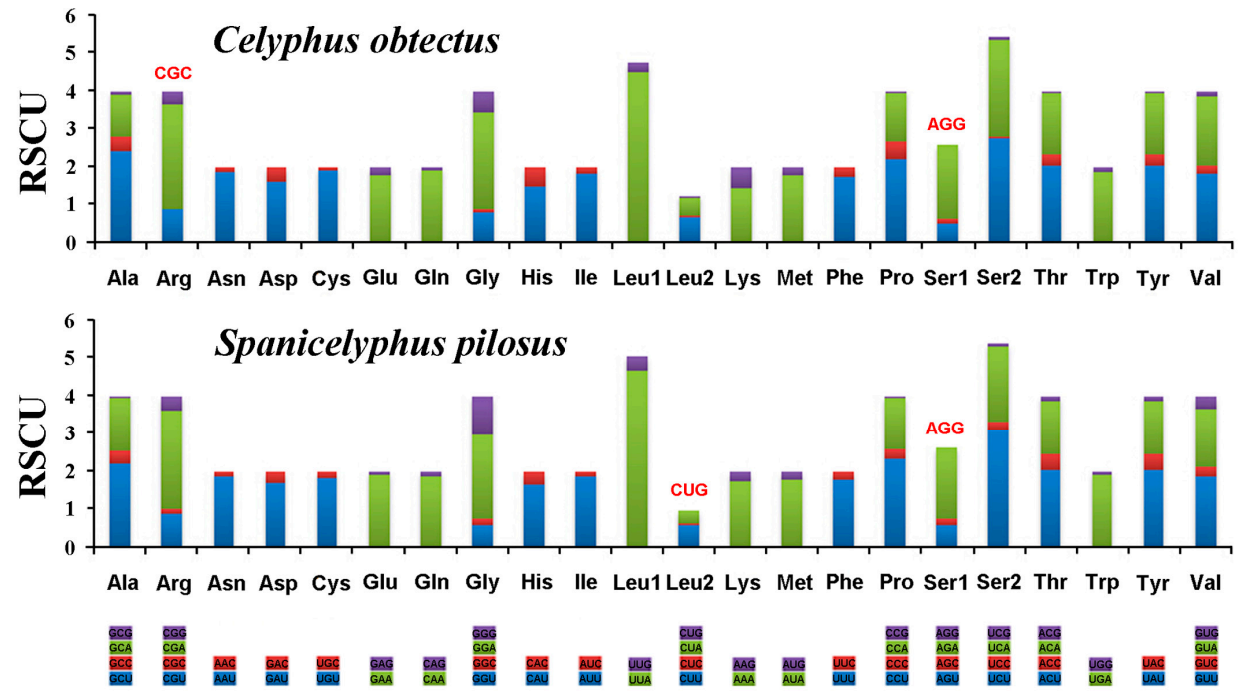

Figure 4. Relative synonymous codon usage (RSCU) in the five lauxanioid mt genomes. Codon families are provided on the $X$-axis. Stop codon is not given. Red codon, codon not present in the chain/genome. 


\subsection{Intergenic Sequences}

Two 18 bp intergenic sequences, highly conserved at the sequence level across the Cyclorrhapha, have been previously reported: between $N D 1-t R N A^{\text {Ser }(U C N)}$ and between $t R N A^{G l u}-t R N A^{\text {Phe }}$ [30]. Similar to all the other Cyclorrhapha, the five lauxanioid flies also have these two conserved intergenic spacers. For the spacer between $N D 1$ and $t R N A^{\text {Ser }(U C N)}$, all five lauxanioid flies have the $18 \mathrm{bp}$ conserved sequence, but Pachycerina decemlineata has an additional $6 \mathrm{bp}$ "TAAACT" at the $5^{\prime}$ end (N-strand), while Cestrotus liui and Chamaemyia juncorum have a redundant " $\mathrm{A}$ " at the $3^{\prime}$ end (N-strand). The conserved sequence region for this spacer in the Lauxanioidea is "TATBAAWWWWWWWTAGTA" (Figure S1A). For the spacer between $t R N A^{G l u}$ and $t R N A^{\text {Phe }}$, Cestrotus liui and Chamaemyia juncorum have 22 and $25 \mathrm{bp}$ intergenic sequences, respectively, while the basic $18 \mathrm{bp}$ motif found across Cyclorrhapha is found in the other three species. The consensus sequence of this $18 \mathrm{bp}$ motif is "ACTWAWWWWAWTTMWHWA" (Figure S1B).

In addition to these two spacer regions, another non-coding region between $t R N A^{\text {His }}$ and ND5 widely conserved in the Cyclorrhapha was detected in this study (Figure 5), which is often 15 bp in length with only three exceptions (14 bp in Fergusonina taylori, Fergusoninidae [14] and Bactrocera minax, Tephritidae [20] and $18 \mathrm{bp}$ in Ceratitis capitata, Tephritidae [23]). The consensus sequence for this spacer amongst the lauxanioid flies was "GTGAAWWWTTTATCM" (Figure S1C). A non-coding region between $t R N A^{\text {His }}$ and ND5 has been previously reported by Yang et al. [16], based on an analysis of 25 cyclorrhaphan mt genomes, with a 7 bp conserved motif. In the present study, a conserved $15 \mathrm{bp}$ region was confirmed as present in all 79 available cyclorrhaphan $\mathrm{mt}$ genomes. More research is needed to determine the functions of conserved non-coding region in insect genomes, although the ND1-tRNA $A^{\text {Ser }(U C N)}$ spacer has been proposed as a likely translation termination site, mtTERM, that controls overexpression of the rRNA genes relative to the protein-coding genes [58,59].

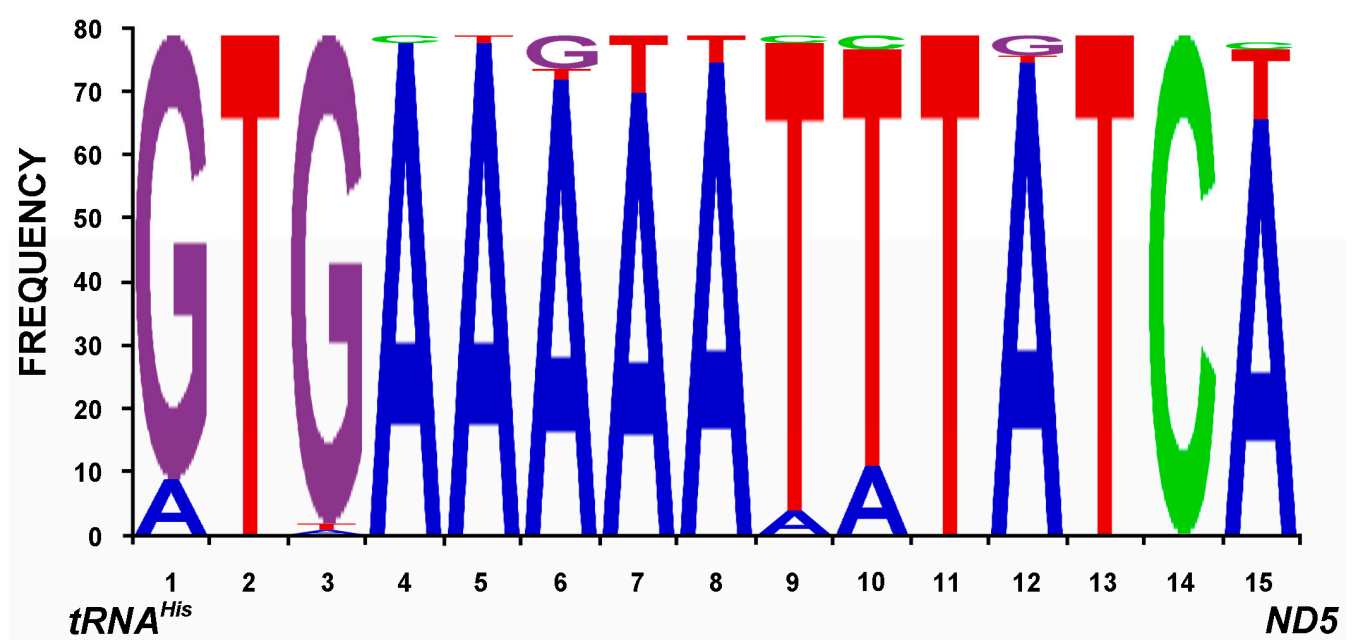

Figure 5. Conserved intergenic sequences between $t R N A^{H i s}$ and ND5, reversed sequences.

\subsection{Transfer RNAs}

All 22 typical tRNAs found in the arthropod $m t$ genomes were found in the three complete lauxanioid mt genomes, while 19 and 20 tRNAs were detected in the two partial genomes. Most tRNAs could be folded into the typical clover-leaf structure (Figure 6), while $t R N A^{\text {Ser }}(A G N)$ was an exception as it lacks a DHU arm, as has been observed in other metazoan $\mathrm{mt}$ genomes [60]. The combined length of all tRNAs was 1474 bp in Cestrotus liui, 1464 bp in Pachycerina decemlineata and $1467 \mathrm{bp}$ in Spanicelyphus pilosus, which are medium-sized totals when compared with the mt genomes of other Cyclorrhapha for which total tRNA size ranges from 1450 bp (Rutilia goerlingiana, Tachinidae [14]) to 1499 bp (Procecidochares utilis, Tephritidae, Wu et al. unpublished). 

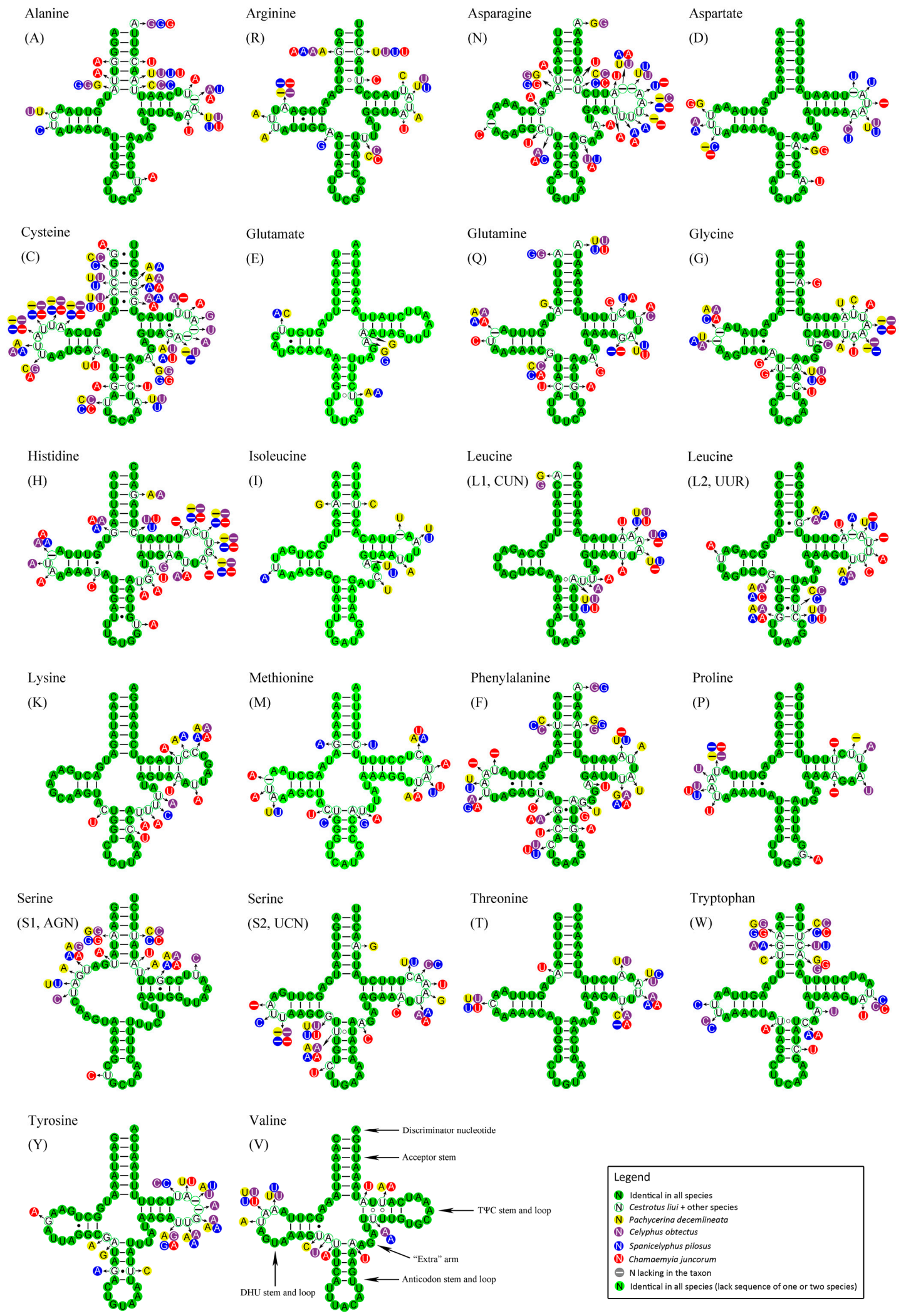

Figure 6. Putative secondary structures of tRNAs found in the five lauxanioid mt genomes. All tRNAs can be folded into the usual clover-leaf secondary structure. The tRNAs are labelled with the abbreviations of their corresponding amino acids. Inferred Watson-Crick bonds are illustrated by lines, whereas guanine-uracil (GU) bonds are illustrated by dots. The lauxanioid substitution pattern for each tRNA was modeled using as reference the structure determined for Cestrotus liui. 
A comparative analysis of the secondary structures of lauxanioid tRNAs was performed (Figure 6). The presence of mismatches in some tRNAs stems is a common molecular feature of arthropod mt genomes. The correct folding of paired structures is thought to be restored through post-transcriptional editing processes [61] or may represent unusual pairings [62]. Mismatches were also detected in the tRNAs of the five lauxanioid (Figure 6, Table S3). One U-U pair in the acceptor stem of $t R N A^{A r g}$ was conserved among four of five lauxanioid genomes, but was present as a U-C pair in Chamaemyia juncorum. The TYC stem of $t R N A^{V a l}$ had at least one U-U pair (all lauxanioid), and in one species (Cestrotus liui) had two pairs. The position of the U-U pair varied between second and third position in the stem in those species with only a single U-U pair.

In order to model the substitution patterns found in tRNAs, Negrisolo et al. [63] proposed two patterns: fully compensatory base changes (cbcs) (e.g., G-C to A-U) and hemi-cbc (e.g., G-U to A-U). Here we observed three more patterns: (1) reparative base changes (rbcs) which restore canonical pairs in a subset of taxa for a position where the majority of taxa lack canonical pairs (e.g., A-A to A-U on the anticodon stem of $t R N A^{\text {Leu }}(C U N)$ ); (2) mirrored base changes (mbcs), a subset of fully cbcs for which the intermediate state is a non-canonical pair rather than a hemi-cbc pair (e.g., A-U to $\mathrm{U}-\mathrm{A}$ as found in the acceptor stem of $t R N A^{\text {Ser }(A G N)}$ in Chamaemyia juncorum); and (3) non-reparative base change (nrbcs), or substitutions from one non-canonical pair to another (e.g., $\mathrm{U}-\mathrm{U}$ to $\mathrm{U}-\mathrm{C}$ in the acceptor stem of $t R N A^{A r g}$ in Chamaemyia juncorum). All the stem-base changes observed in lauxanioid mt tRNA genes could be described by these five patterns, while the substitution changes on loops cannot be modeled properly due to the high level of variation among species.

The secondary structures of each tRNA genes across the Cyclorrhapha were compared (Figure S2).

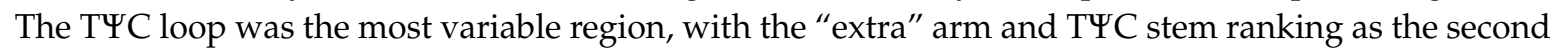
and third most variable. Nucleotides were most conserved in the anticodon loop and DHU stem. Except for anticodon loop, the conservation of each stem was always higher than its corresponding loop. Most cyclorrhaphan tRNAs used the standard anticodon for each gene, but $t R N A^{A s n}$ in Procecidochares utilis (Tephritidae) (Wu et al. unpublished) was predicted to have the anticodon UUU, and $t R N A^{\text {Phe }}$ in Liriomyza huidobrensis (Agromyzidae) [15] used GAG as anticodon. Although the genetic code is nearly universal, more than ten variants have been described in metazoan mt genomes [63-68]. The above two patterns detected in cyclorrhapha mt genomes were unique amongst arthropods, while these variations on "wobble" position within the anticodon did not necessarily make changes to the genetic code.

The percent of identical nucleotides (\%INUC) and the A + T content generated from alignments of tRNAs genes were calculated for the Cyclorrhapha (Figure 7). Amongst the Cyclorrhapha, three of the four most conserved tRNAs (\%INUC $\geq 60), t R N A^{\text {Met }}(74.3 \%), t R N A^{\operatorname{Ser}(A G N)}(60.3 \%)$ and $t R N A^{\text {Thr }}$ $(63.8 \%)$, are located on the J-strand, while only $t R N A^{\text {Val }}(68.1 \%)$ is encoded on the N-strand. Other tRNAs with high level of nucleotide conservation $(55 \leq \%$ INUC $<60)$ include three J-strand tRNAs: $t R N A^{A s p}, t R N A^{G l u}, t R N A^{\text {Leu (UUR) }}$, and two N-strand tRNAs: $t R N A^{\text {Leu }(C U N)}$ and $t R N A^{\text {Pro }}$. On the other hand, $t R N A^{\text {Cys }}(35.1 \%)$, which is encoded on the $\mathrm{N}$-strand, is the least conserved tRNA. Other less conserved tRNAs (\%INUC < 45) include $t R N A^{\text {His }}$ and $t R N A^{\text {Phe }}$ encoded on the $\mathrm{N}$-strand, and $t R N A^{\text {Arg }}$ and $t R N A^{\text {Ile }}$ located on the J-strand. The nucleotide conservation pattern has been reported to have a remarkable J-strand bias in neuropterid tRNAs [62]. However, only a limited J-strand bias was observed in cyclorrhaphan tRNAs, with the J-strand tRNAs having \%INUC ranging 35.3\% to $74.3 \%$ (average 53.4\%), while \%INUC in the N-strand tRNAs was between $35.1 \%$ and $68.1 \%$ (average $50.1 \%$ ). In contrast, the pattern of $\mathrm{A}+\mathrm{T} \%$ showed a modest $\mathrm{N}$-strand bias. The two tRNAs with the highest $\mathrm{A}+\mathrm{T}$ content were $t R N A^{G l u}\left(90.5 \%\right.$, encoded on the $\mathrm{N}$-strand) and $t R N A^{A s p}(88.3 \%$, encoded on the $\mathrm{J}$-strand). Seven of the 11 tRNAs with low $\mathrm{A}+\mathrm{T}$ content $(<75 \%)$ are located on the J-strand, including the two tRNAs with the lowest $\mathrm{A}+\mathrm{T}$ content, $t R N A^{\text {Arg }}(69.8 \%)$ and $t R N A^{L y s}(68.4 \%)$. 


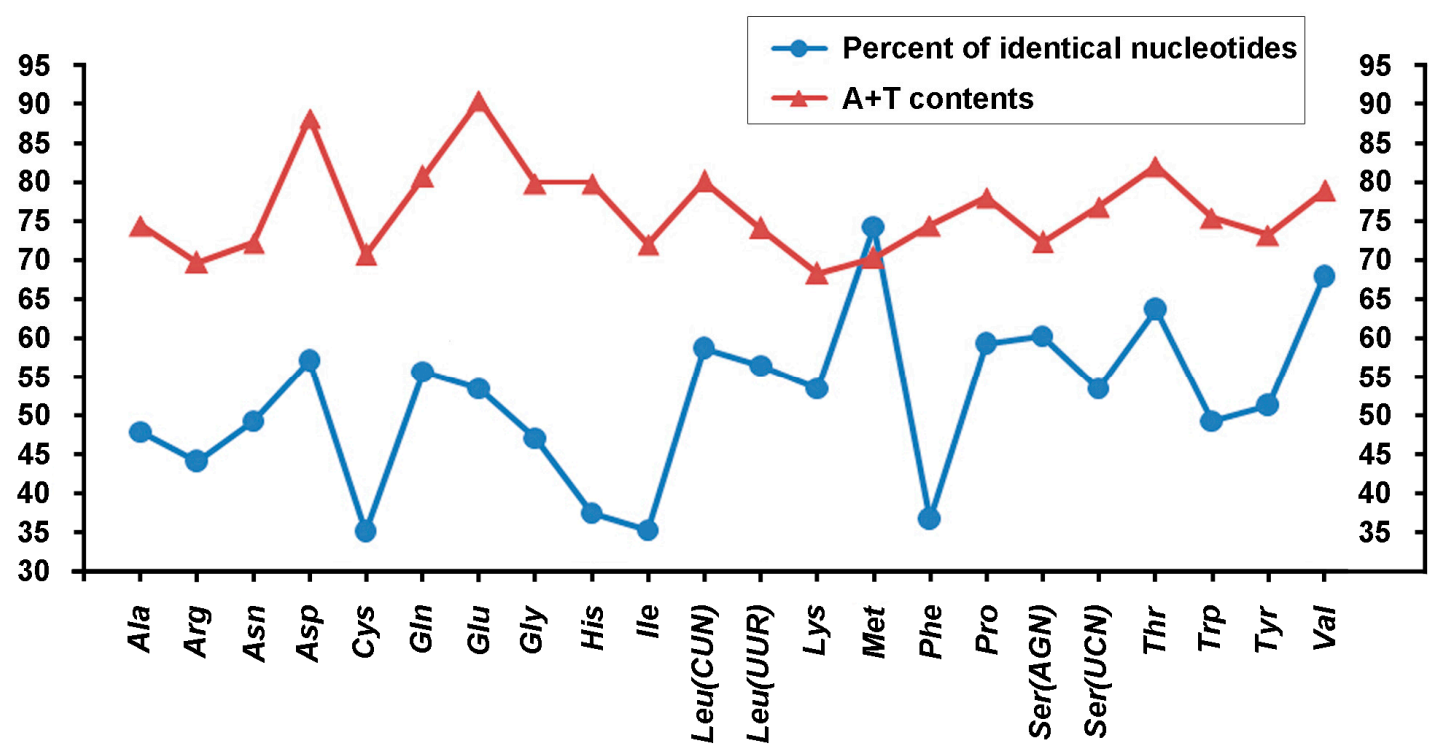

Figure 7. Nucleotides conservation and A + T contents of tRNAs in cyclorrhaphan $\mathrm{mt}$ genomes. Blue circle, percent of identical nucleotides; Red triangle, A + T contents.

No relationships were observed between the \%INUC of a tRNA, and its location relative to either the control region or the mtTERM site the ND1-tRNA ${ }^{\text {Ser }(U C N)}$ space discussed above for neuropterid tRNAs [63]. However, in the present analysis of cylorrhaphan tRNAs, those closest to the control region or either the $t R N A^{G l u}-t R N A^{\text {Phe }}$ or $t R N A^{\text {His }}$-ND5 conserved intergenic spacers, were the least conserved tRNAs ( $\left.t R N A^{\text {His }}(37.5 \%), t R N A^{\text {Ile }}(35.3 \%), t R N A^{\text {Phe }}(36.8 \%)\right)$ (Figures 1 and 7$)$. Additionally, a similar trend was observed between \%INUC and A + T content for cyclorrhaphan tRNAs (Figure 7) with Pearson Correlation Coefficient $=0.21$, which indicated a weak positive correlation between them. In general, tRNAs with higher $\mathrm{A}+\mathrm{T}$ content tended to be more conserved. The two exceptions were $t R N A^{M e t}$ (exceedingly conserved, lower than average $\mathrm{A}+\mathrm{T}$ ) and $t R N A^{\text {Phe }}$ (very low conservation, average $\mathrm{A}+\mathrm{T})$ (Figure 7).

Analysis of tRNA conservation was extended to include all cyclorrhaphan superfamilies with more than two available complete mt genomes (Figure S3A). Different superfamilies exhibited different patterns of \%INUC for their tRNAs. The most conserved tRNA in any superfamily was $t R N A^{\text {Leu }}$ (UUR) in the Muscoidea (95.5\%), while the lowest was $t R N A^{V a l}(47.0 \%)$ in the Opomyzoidea. Across the Cyclorrhapha, a total of 16 tRNAs were found with \%INUC $\geq 90$ in a single superfamily: Ephydroidea (three tRNA genes), Lauxanioidea (two), Oestroidea (two), Tephritoidea (one) and Opomyzoidea (one). Muscoidea tRNAs had the highest level of conservation (from $75.7 \%$ to $95.5 \%$ with an average of $87.2 \%$ ), followed by the Ephydroidea, Lauxanioidea and Opomyzoidea (averages of $83.4 \%, 81.8 \%$ and $80.4 \%$, respectively). The Tephritoidea (from $64.3 \%$ to $94.1 \%$ with an average of $77.5 \%$ ) and Oestroidea (from $57.4 \%$ to $91.7 \%$ with an average of $77.1 \%$ ) had the least conserved tRNAs. The results of the $\mathrm{A}+\mathrm{T}$ content analysis from these cyclorrhaphan superfamilies are summarized in Figure S3B. A similar pattern of $\mathrm{A}+\mathrm{T}$ content was observed, $t R N A^{\text {Lys }}$ often had the lowest $\mathrm{A}+\mathrm{T}$ content (in Tephritoidea, Opomyzoidea, Muscoidea, Oestroidea and Cyclorrhapha), while $t R N A^{\text {Glu }}$ often had the highest (in Ephydroidea, Opomyzoidea, Muscoidea, Oestroidea and Cyclorrhapha).

\subsection{Ribosomal RNAs}

Among the five lauxanioid $\mathrm{mt}$ genomes, the length of $\operatorname{lr} R N A$ ranges from $1312 \mathrm{bp}$ (Chamaemyia juncorum) to $1334 \mathrm{bp}$ (Cestrotus liui), and the lengths of srRNAs are $786 \mathrm{bp}$ (Cestrotus liui), $788 \mathrm{bp}$ (Pachycerina decemlineata) and $793 \mathrm{bp}$ (Spanicelyphus pilosus) (the complete srRNA could not be amplified for the other two species). Both subunits of rRNA are encoded on the N-strand as in other insects. Unlike PCGs with functional annotation features like start and stop codons, it is difficult 
to determine the boundaries from rRNA gene sequences alone [29,69], therefore, the boundaries of flanking genes were used by assuming no overlapping or gaps located between adjacent genes. As in

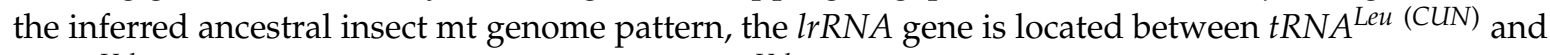
$t R N A^{V a l}$, while the $\operatorname{sr} R N A$ gene is between $t R N A^{\mathrm{Val}}$ and the control region.

Secondary structures of both subunits of rRNA of Cestrotus liui $\mathrm{mt}$ genome were inferred using published rRNA secondary structures of N. mamevi [30] in Figures 8 and 9, with nucleotides conserved among the five lauxanioid $\mathrm{mt}$ genomes shown in solid circles. The $\operatorname{lr} R N A$ had 43 helices in five structural domains (I-II, IV-VI, domain III is absent as in other insects). The multiple alignments of lauxanioid lrRNAs spanned 1350 positions and contained 974 conserved (with the same nucleotide in all five lauxanioid $l r R N A s)(72.1 \%$ ) and 376 variable positions (with at least one different nucleotide amongst five lauxanioid $\operatorname{lr} R N A s)(27.9 \%)$, respectively (Figure 8 ). The srRNA included three domains and 34 helices. The multiple alignment of lauxanioid srRNAs extended over 795 positions and contained 582 conserved $(73.2 \%)$ and 213 variable sites (26.8\%) (Figure 9). Secondary structures of all mt rRNAs from the Cyclorrhapha were inferred in Figures S4 and S5. Nucleotide conservation of the two rRNA genes was unevenly distributed among structural domains. Domains IV and V in $\operatorname{lr} R N A$ were more conserved than other domains, while the most conserved domain in $\operatorname{sr} R A$ was domain III (Figures S4 and S5).

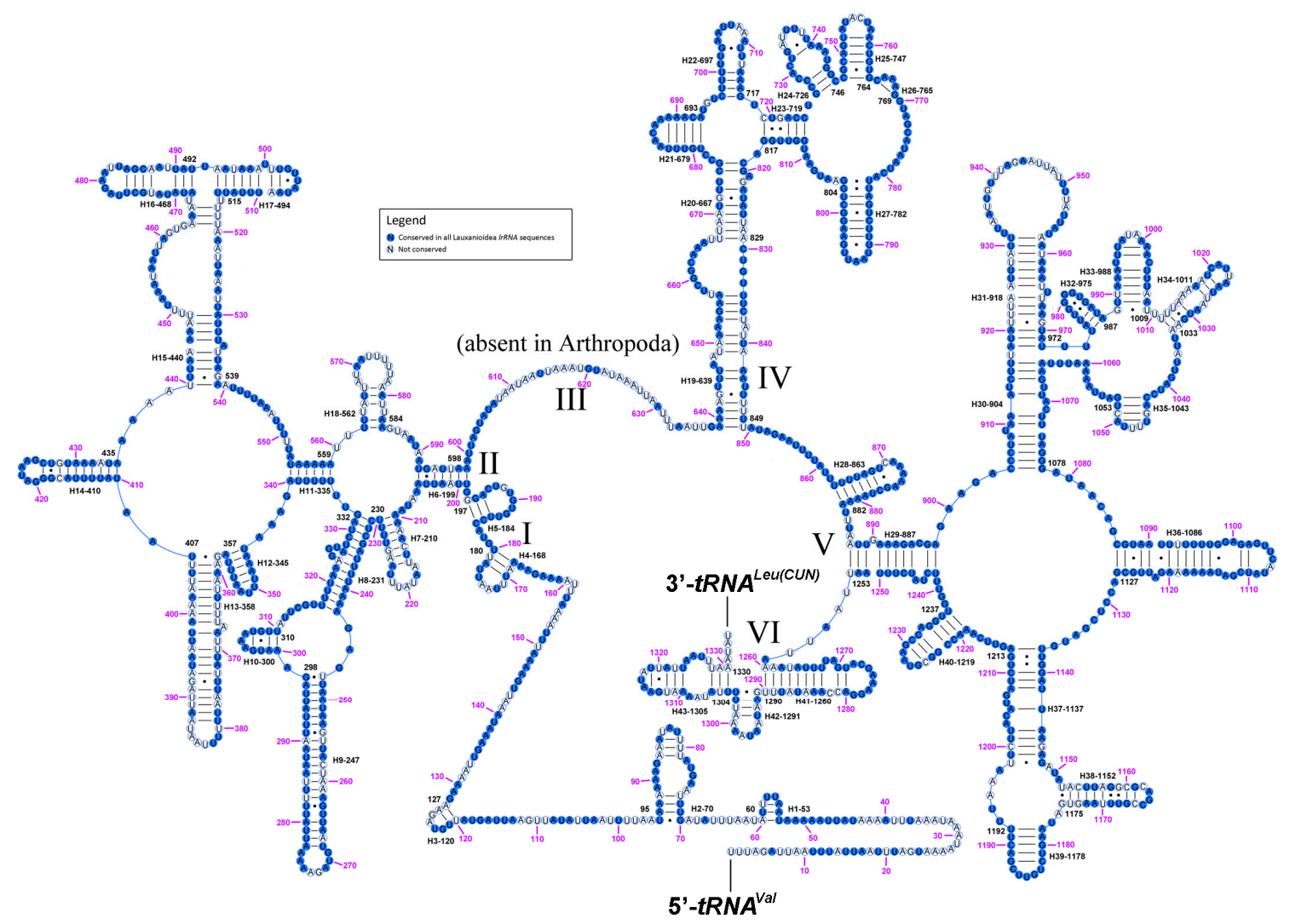

Figure 8. Predicted secondary structure of the $\operatorname{lr} R N A$ gene in Cestrotus liui. Filled circle, nucleotide conserved in five lauxanioid $\mathrm{mt}$ genomes; hollowed circle, nucleotide not conserved. Each helix is numbered progressively from $5^{\prime}$ to the $3^{\prime}$ end together with the first nucleotide belonging to the helix itself. Domains are labeled with Roman numerals. Inferred Watson-Crick bonds are illustrated by lines, GU bonds by dots. 


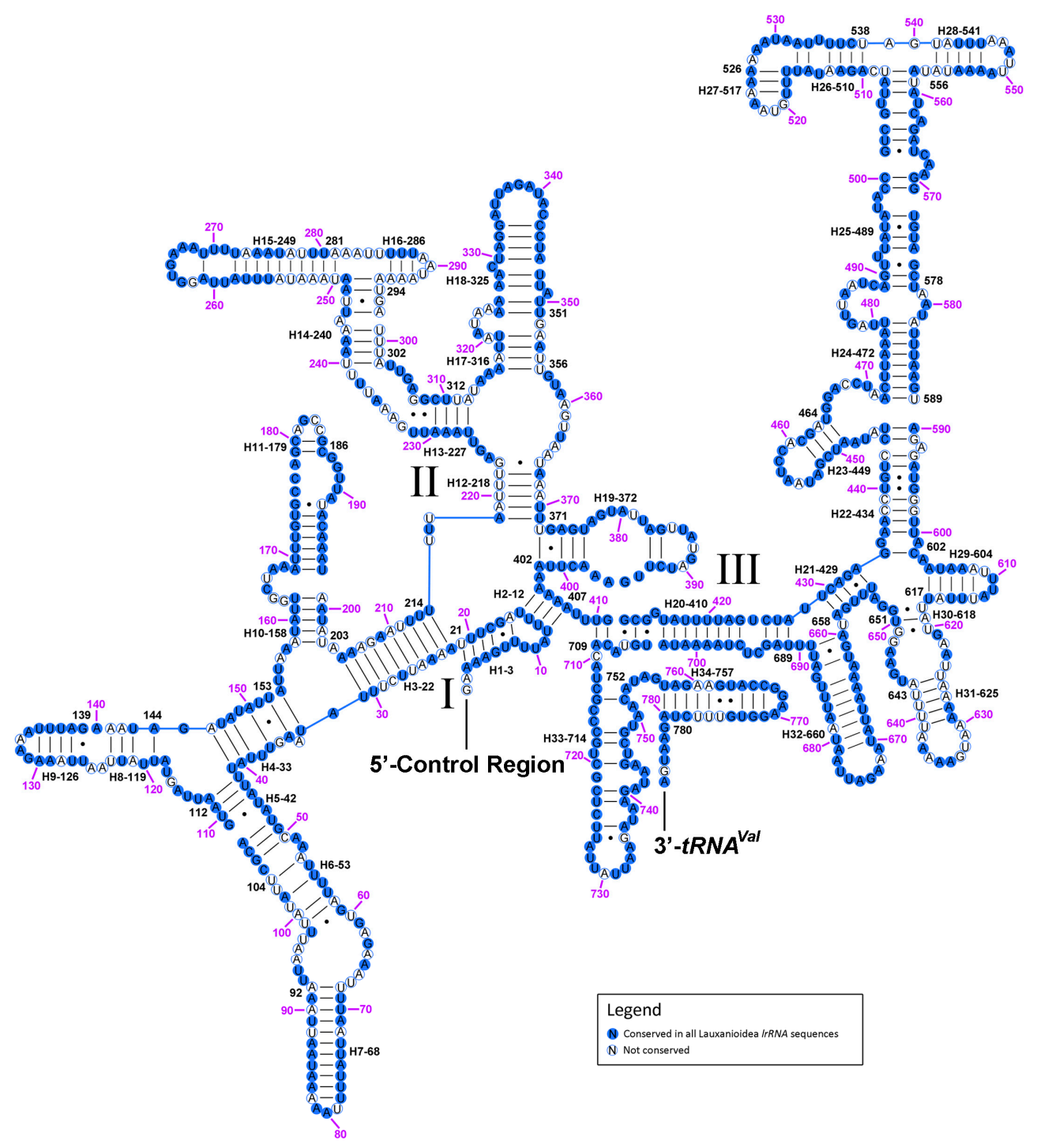

Figure 9. Predicted secondary structure of the srRNA gene in Cestrotus liui. Filled circle, nucleotide conserved in five lauxanioid mt genomes; hollowed circle, nucleotide not conserved. Each helix is numbered progressively from $5^{\prime}$ to the $3^{\prime}$ end together with the first nucleotide belonging to the helix itself. Domains are labeled with Roman numerals. Inferred Watson-Crick bonds are illustrated by lines, GU bonds by dots.

Further analyses of the levels of nucleotide conservation and A + T content in the rRNAs were performed across the Cyclorrhapha as well as for each cyclorrhaphan superfamily with more than two available complete mt genomes (Figure S6). A similar positive correlation between \%INUC and A + T content as that observed in tRNAs was detected from the rRNAs (Pearson Correlation Coefficient $=0.6$ in $\operatorname{lr} R N A$ and 0.8 in $s r R N A$ ). An extremely high \%INUC was observed in the superfamily Ephydroidea, mainly due to all 14 available mt genomes for the Ephydroidea belonging to species from the same genus, Drosophila. The conservation of $\operatorname{lr} R N A$ amongst the Cyclorrhapha was $41.9 \%$, while it was much lower for srRNA (31.0\%). The Opomyzoidea had the highest A + T content in both rRNAs (83.2\% in $\operatorname{lr} R N A$ and $80.7 \%$ in $s r R N A$, respectively), and the rRNAs with the lowest $\mathrm{A}+\mathrm{T}$ content belonged to the Tephritoidea (79.6\% in $l r R N A$ and $83.2 \%$ in $s r R N A$, respectively). In general, the level of nucleotide conservation of $\operatorname{lr} R N A$, as well as $\mathrm{A}+\mathrm{T}$ content, were higher than those of srRNA, except for the Lauxanioidea where nucleotide conservation of $s r R N A s$ was slightly higher than that of $\operatorname{lr} R N A s$ (Figure S6). 


\subsection{The Control Region}

The control region is the longest non-coding region, located at the ancestral insect position between $\operatorname{sr} R N A$ and $t R N A^{\text {Ile }}$. Among the three complete lauxanioid mt genomes, the control regions range in size from $1266 \mathrm{bp}$ (Cestrotus liui) to $1541 \mathrm{bp}$ (Spanicelyphus pilosus). Four conserved structure elements were detected from all three completely sequenced control regions: (1) a poly-T stretch towards the middle of the control region (15 bp long in Cestrotus liui, $12 \mathrm{bp}$ in Pachycerina decemlineata and 11 bp in Spanicelyphus pilosus); (2) a (TA) ${ }_{n}$-like stretch close to the poly-T stretch; (3) a poly-A stretch near the 3'-end of control region (13 bp in Cestrotus liui, 13 bp in Pachycerina decemlineata and $16 \mathrm{bp}$ in Spanicelyphus pilosus); and, (4) a stem-loop structure at the $3^{\prime}$-end of the control region, that lacks both the $5^{\prime}$ "TATA" and $3^{\prime}$ "G(A) $\mathrm{T}_{n}$ " consensus regions found in other insect mt control regions (Figure 10A,B).
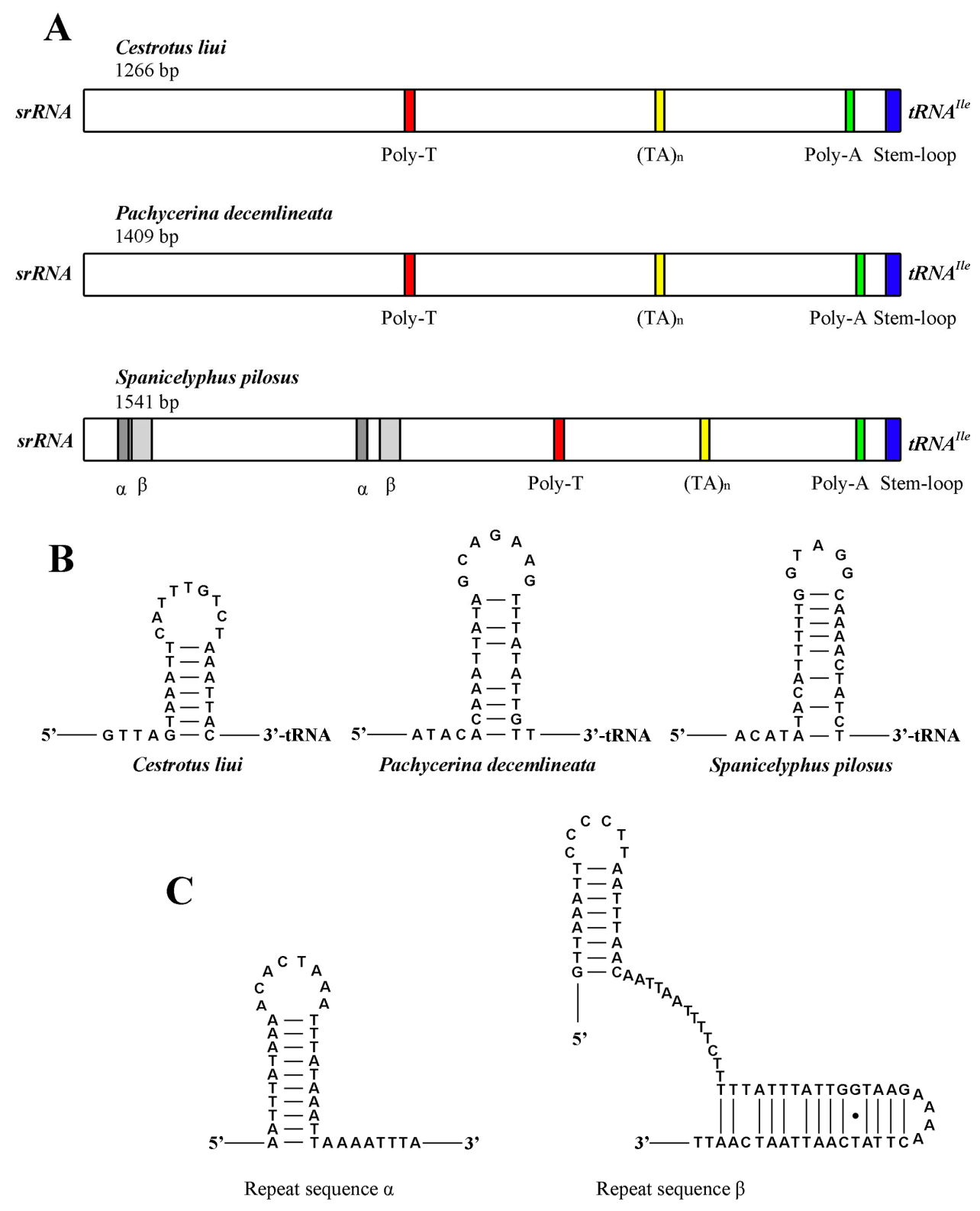

Figure 10. Predicted structure elements in the control region of Cestrotus liui, Pachycerina decemlineata, Spanicelyphus pilosus. (A) Control region structure of three species; (B) secondary structures of stem-loop structure at $3^{\prime}$-end of the control region; (C) secondary structures of repeat sequences of Spanicelyphus pilosus. Inferred Watson-Crick bonds are illustrated by lines, GU bonds by dots. 
Two long non-tandem macro repeats ( $72 \mathrm{bp}$ and $36 \mathrm{bp}$, respectively) were found in the control region of Spanicelyphus pilosus: 5'-GTTAAATTCCCCTTAATTTAACAATTAATTTTCTTTTATTTA TTGGTAAGAAAACTTATCAATTAATCAATT-3' (from positions 199 to 270, and 584 to 655); and 5'-AATTTATAAAACACTAAATTTATAAATTAAAATTTA-3' (from positions 162 to 197, and 547 to 582). Both macro repeats could be folded into stem-loop structures (Figure 10C). Additionally, several relatively short non-tandem repeats were detected from all three species, accompanied by a short $(\mathrm{TA})_{n}$-like stretch. These (TA) ${ }_{n}$-like stretches can easily form stem-loop structures and might play roles in influence replication and transcription.

\subsection{Phylogeny}

Four datasets, varying by the inclusion and exclusion of different nucleotide classes, were used in the phylogenetic analysis. The four datasets are the P123 matrix (containing nucleotides of 13 PCGs) consisting of 10,977 residues, the P123R matrix (containing nucleotides of 13 PCGs, two rRNAs and 19 tRNAs) consisting of 13,903 residues, the P12 matrix (containing nucleotides of 13 PCGs but excluding the third codon sites) consisting of 7318 residues and the P12R matrix (containing nucleotides of 13 PCGs but excluding the third codon sites, two rRNAs and 19 tRNAs) consisting of 10,244 residues.

The phylogenetic trees inferred from both Bayesian and Maximum Likelihood (ML) analyses yield a consensus topology across the four datasets with the majority of nodes supported by all datasets and analyses (Figure 11A); all eight trees are shown in Table S7; discordant nodes will be discussed below. The monophyly of the Opomyzoidea, Tephritoidea, Ephydroidea and Calyptratae were consistently supported (posterior probability $=1.00$ all datasets, ML bootstrap $=100$ all datasets), as was the monophyly of the Brachycera (posterior probability $=1.00$, ML bootstrap $=99 / 99 / 98 / 100$ for the $\mathrm{P} 123 / \mathrm{P} 123 \mathrm{R} / \mathrm{P} 12 / \mathrm{P} 12 \mathrm{R}$ datasets) and Cyclorrhapha (posterior probability $=0.99 / 1.00 / 0.99 / 1.00$, ML bootstrap = 83/100/84/100). "Aschiza" was not monophyletic, and the Phoridae was the sister group of the remaining Cyclorrhapha (posterior probability $=1.00$, ML bootstrap $=100 / 100 / 100 / 99$ ), which is widely accepted by previous studies [48,50,70-73]. As has previously been found by Wiegmann et al. [51], (Ephydroidea + Calyptratae) formed a monophyletic group (posterior probability $=1.00$, ML bootstrap $=83 / 93 / 78 / 96$ ).

Similar to our previous analyses [30], the relationships between families in the Muscoidea (represented by the families Muscidae and Scathophagidae) and Oestroidea (represented by the families Oestridae, Tachinidae, Calliphoridae and Sarcophagidae) are highly discordant between the eight phylogenetic trees. Since it was specially analyzed by Ding et al. [33], two more muscoidean families are included here (Anthomyiidae and Fanniidae), relationships within the Calyptratae will not be discussed in this paper. Although contrary to some previous mt genome trees of the Diptera [7], the monophyly of the included "orthorrhaphan" taxa (Nemestrinidae and Tabanidae) was not supported by most of our analyses (except the BI-P123 (dataset P123 with Bayesian analysis), ML-P123and ML-P123R analyses) (Figure 11A); this is in accordance with more recent $\mathrm{mt}$ genome phylogenies of the lower Brachycera [74]. The paraphyly of "Orthorrhapha" has been widely recognized (e.g., [51,53,72]) and the Tabanidae (which belongs to the Tabanomorpha) has been considered to have a more basal position within the "Orthorrhapha" grade than the Nemestrinidae (typically assigned to the Asilomorpha but highly variable its phylogenetic position across different studies) [48,71]. 


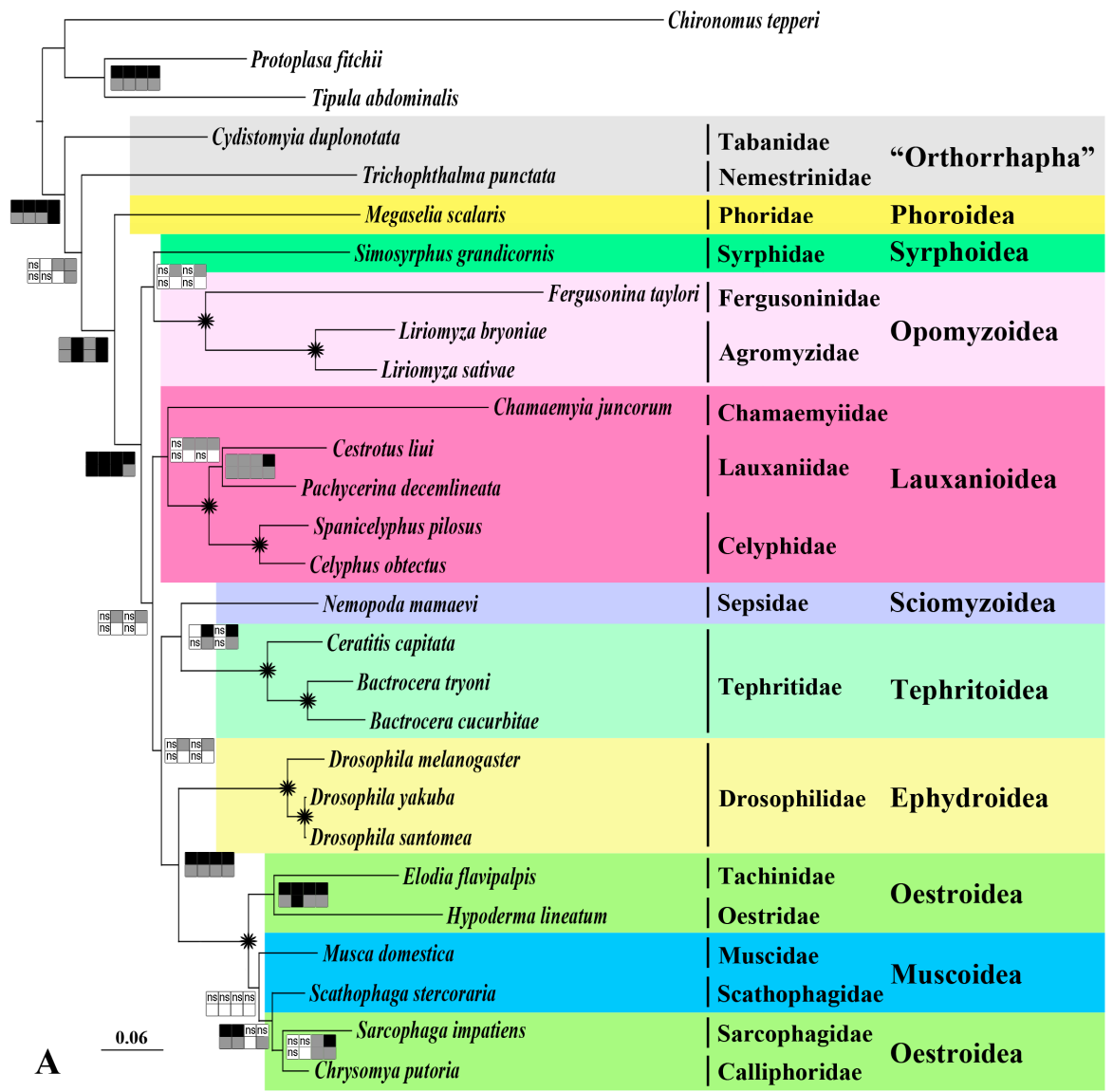

P12R-ML, P123R-ML, P12-BI, P12R-BI, P123R-BI

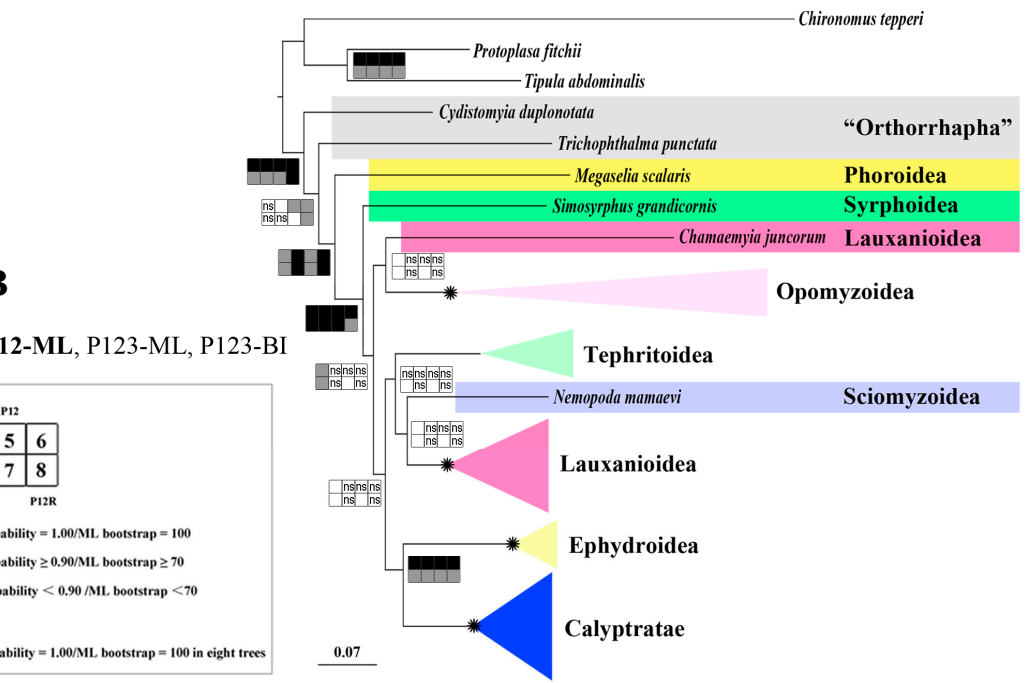

Figure 11. Phylogenetic trees of Brachycera families based on $\mathrm{mt}$ genome data. (A) Brachycera phylogeny obtained from the ML inferences based on P12R dataset, topology similar to P123R-ML, P12R-BI and P123R-BI; (B) Brachycera phylogeny obtained from the ML inferences based on P12 dataset, topology similar to P123-ML and P123BI. Cladogram of relationships with Tipula abdominalis (Tipulidae), Chironomus tepperi (Chironomidae) and Protoplasa fitchii (Tanyderidae) as outgroups. Squares at the nodes are Bayesian posterior probabilities for 1, 2, 5 and 6, ML bootstrap values for 3, 4, 7 and 8 . Dataset of P123, 1 and 3, P123R, 2 and 4,P12, 5 and 7, P12R, 6 and 8. Black indicates posterior probabilities $=1.00$ or ML bootstrap $=100$; oblique lines indicates posterior probabilities $\geq 0.90,<1.00$ or ML bootstrap $\geq 70,<100$; white indicates posterior probabilities $<0.90, \geq 0.50$ or ML bootstrap $<70, \geq 50$; "ns" indicates posterior probabilities $<0.50$ or ML bootstrap $<50$, not supported, * indicates posterior probabilities $=1.00$ or ML bootstrap $=100$ in eight trees. 
The superfamily Lauxanioidea formed a monophyletic group in five of the eight analyses (posterior probability $=\mathrm{ns} / 0.99 / 0.98 / 0.99$, ML bootstrap $=\mathrm{ns} / 51 / \mathrm{ns} / 54$ ) $($ Figure 11A). However, the other three analyses recovered a sister relationship between Chamaemyiidae and Opomyzoidea but without significant nodal support (posterior probability $=0.60 / \mathrm{ns} / \mathrm{ns} / \mathrm{ns}$, ML bootstrap $=36 / \mathrm{ns} / 36 / \mathrm{ns}$ ) (Figure 11B). Amongst the superfamily Lauxanioidea, the monophyly of Celyphidae and its sister relationship to the Lauxaniidae were consistently and strongly supported (posterior probability $=1.00$, ML bootstrap $=100$ ), as was the monophyly of Lauxaniidae (posterior probability $=0.97 / 0.99 / 0.99 / 1.00$, ML bootstrap $=71 / 73 / 78 / 86)$. This relationship (Chamaemyiidae + (Lauxaniidae + Celyphidae)), although relatively weakly supported here, supports the relationships proposed by McAlpine [49] for the superfamily. The inclusion of RNAs in the mitochondrial phylogenetic analysis has been shown to be beneficial in improving nodal confidence [12] or even stabilizing highly variable backbone relationships [5]. Here, the BI-P123, ML-P123 and ML-P12 datasets all failed to resolve the monophyly of the Lauxanioidea suggesting that the exclusion of RNAs is responsible for its non-monophyly in these analyses.

The backbone phylogeny of the Cyclorrhapha, however, was not well resolved in our analyses based on $\mathrm{mt}$ genome data. There are low nodal support values and/or conflict between datasets for many of the superfamily-level nodes. The clade (Sciomyzoidea + Tephritoidea) was only supported by datasets including RNAs (posterior probability $=0.6 / 1.0 / \mathrm{ns} / 1.0$, ML bootstrap $=\mathrm{ns} / 86 / \mathrm{ns} / 84$ ), and was the weakly supported sister-group to the clade (Ephydroidea + Calyptratae) (posterior probability $=\mathrm{ns} / 0.99 / \mathrm{ns} / 0.99$, ML bootstrap $=\mathrm{ns} / 58 / \mathrm{ns} / 58)$. The Lauxanioidea was sister to this derived set of superfamilies ((Sciomyzoidea + Tephritoidea) + (Ephydroidea + Calyptratae)); however, nodal support was weak (posterior probability $=\mathrm{ns} / 0.99 / \mathrm{ns} / 0.99$, ML bootstrap $=\mathrm{ns} / 50 / \mathrm{ns} / 46$ ) and again confined to datasets which include RNAs (Figure 11A). Schizophora including Syrphoidea was strongly monophyletic (posterior probability $=1.00$, ML bootstrap $=100 / 100 / 100 / 99)($ Figure 11A). This topology is also supported by Wiegmann et al. [51], which, however, did not recover a monophyletic Syrphoidea. Datasets which excluded RNAs indicated a different topology but with very low nodal supports for most of the main nodes (Figure 11B), as in Wiegmann et al.'s [51] analysis. However, the representative of Sciomyzoidea used here, Sepsidae, was more closely related to the Tephritoidea in Wiegmann et al.'s study [51], as opposed to being the sister of Lauxanioidea as in the present study.

The placement of Syrphoidea was weakly supported in both topologies. Either the Syrphoidea and the Opomyzoidea formed a clade (posterior probability $=\mathrm{ns} / 0.98 / \mathrm{ns} / 0.97$, ML bootstrap $=\mathrm{ns} / 53 / \mathrm{ns} / 49$ ), thus rendering the Schizophora non-monophyletic (Figure 11A), or the Syrphoidea was sister to the Schizophora (posterior probability $=0.96 / \mathrm{ns} / \mathrm{ns} / \mathrm{ns}$, ML bootstrap $=72 / \mathrm{ns} / 63 / \mathrm{ns}$ ) (Figure 11B).

The relationships between acalyptrate fly families (i.e. Schiziphora excluding the Calyptratae) have been contentious and vary significantly between different phylogenetic analyses. The present study contributes to our efforts to understand these relationships while providing additional evidence that the inclusion of RNA genes in $\mathrm{mt}$ genome-based phylogenetic studies improves resolution [2]. A more comprehensive dataset using transcriptome or even genome data combined with morphological characters should be included in future studies.

\section{Materials and Methods}

\subsection{Ethics Statement}

No specific permits were required for the insects collected for this study. The specimen was collected by using sweeping method. The field studies did not involve endangered or protected species. The species herein studied are not included in the "List of Protected Animals in China". 


\subsection{Sampling and DNA Extraction}

The collection information for specimens used in this study is provided in Table S4. After collection, specimens were initially preserved in $95 \%$ ethanol in the field, and then transferred to $-20^{\circ} \mathrm{C}$ for the long-term storage upon the arrival at China Agricultural University (Beijng, China). Lauxaniidae specimens were examined and identified by Wenliang $\mathrm{Li}$, Celyphidae specimens were examined and identified by Jinying Yang, Chamaemyiidae specimens were examined and identified by the first author Xuankun Li with a ZEISS Stemi 2000-c microscope (ZEISS, Jena, Germany). Whole genomic DNA was extracted from the thoracic muscle tissues using TIANamp Genomic DNA Kit (TIANGEN, Beijing, China). The quality of PCR products was assessed through electrophoresis in a $1 \%$ agarose gel and stained with Gold View (ACME, Beijing, China).

\subsection{PCR Amplification and Sequencing}

For each species, the mt genome was amplified by PCR in overlapping fragments using universal Diptera mt primers [7], and species-specific primers designed from sequenced fragments. All primers used in the present study are listed in Table S5. NEB Long Taq DNA polymerase (New England BioLabs, Ipswich, Suffolk, UK) was used to amplify PCR fragments.

PCR cycling consisted of an initial denaturation step at $95^{\circ} \mathrm{C}$ for $30 \mathrm{~s}$, followed by 40 cycles of denaturation at $95^{\circ} \mathrm{C}$ for $10 \mathrm{~s}$, annealing at $42-55^{\circ} \mathrm{C}$ (depending on the primer pair used) for $50 \mathrm{~s}$, elongation at $65^{\circ} \mathrm{C}$ for $1 \mathrm{~KB} / \mathrm{min}$ (depending on the size of target amplicon) (Table S1), and a final elongation step at $65^{\circ} \mathrm{C}$ for $10 \mathrm{~min}$. PCR products were evaluated by agarose gel electrophoreses.

All amplicons were sequenced in both directions using the BigDye Terminator Sequencing Kit (Applied Bio Systems, Waltham, MA, USA) and the ABI 3730XL Genetic Analyzer (PE Applied Biosystems, San Francisco, CA, USA) with two vector-specific primers and internal primers developed by primer walking.

\subsection{Bioinformatic Analysis}

Sequences were proofread and aligned into contigs in BioEdit version 7.0.5.3 [75]. After fully sequencing the mt genome, tRNA genes were identified with tRNAscan-SE 1.21 [76] with a cove cutoff score of 1 and the prediction of the genetic code followed the invertebrate mitochondrial DNA. tRNA genes not detected in this way were identified by comparison with multiple sequence alignments of the tRNAs in Cyclorrhapha. The secondary structures of tRNAs were also estimated by tRNAscan-SE Search Server v.1.21 [76], under the principles described by Lowe and Eddy [77].

Hand annotation method followed the procedures proposed by Cameron [3] plus modified quality control for partial stop codon by Li et al. [30]. The rRNA genes and the control region were identified by their boundaries with tRNA genes and comparison with other insect $\mathrm{mt}$ genomes.

The tRNAs' secondary structures were identified by tRNAscan-SE Search Server v.1.21 [76], and the rRNAs were inferred using models for Drosophila melanogaster [26]. The secondary structures of RNAs are dependent on environmental conditions and, as presented, the RNAs' secondary structures are primarily intended to show the substitution patterns within tRNAs as well as the conserved regions within rRNAs.

Nucleotide substitution rates, base composition and codon usage were analyzed with MEGA 5.0 [77]. Nucleotide compositional skew was measured using the following formula: AT-skew $=(\mathrm{A}-\mathrm{T}) /(\mathrm{A}+\mathrm{T})[78]$.

\subsection{Phylogenetic Analysis}

A total of 28 species of dipteran insects were used in phylogenetic analysis, including 25 brachycerans and three outgroup species from the "nematocera": one species each from the families Tipulidae, Chironomidae and Tanyderidae. Details of the species used in this study are listed in Table 1. 
Sequences of the 13 PCGs, two rRNAs and 19 tRNAs were used in phylogenetic analysis. Three tRNAs which were not available in all sampled dipterans were excluded: $t R N A^{\text {lle }}, t R N A^{\text {Gln }}$ and $t R N A^{\text {Met }}$. The MAFFT algorithm in the TranslatorX online platform (http://translatorx.co.uk/) [79] under the L-INS-i strategy was utilized to align PCGs using codon-based multiple alignments and to toggle back to the nucleotide sequences. Before back-translating to nucleotides, poorly aligned sites were removed from the protein alignment using GBlocks v0.91b (http://molevol. cmima.csic.es/castresana/Gblocks_server.html) [80] as implemented in TranslatorX with default settings. MXSCARNA [81] was used to align tRNA genes based on the predicted secondary structures. The Muscle algorithm [82] as implemented in MEGA 5.0 [77] was performed to align the two rRNAs, and ambiguous positions in the alignment were filtered by hand based on the secondary structures predicted. Individual genes were concatenated using SequenceMatrix v1.7.8 [83]. We assembled four datasets for phylogenetic analysis: (1) all codon positions for the 13 PCGs (P123) 10,977 bp; (2) all codon positions for the 13 PCGs, plus the two rRNAs and 19 tRNAs (P123R) 13,903 bp; (3) the P123 dataset excluding third codon positions (P12) $7318 \mathrm{bp}$; and (4) the P123R dataset excluding third codon positions (P12R) 10,244 bp.

The optimal partition strategy and substitution models for each partition were selected by PartitionFinder v1.1.1 [84]. As the software requires the user to predefine partitions, we created input configuration files for the four datasets: (1) 39 partitions (three codon positions for each of the 13 PCGs) for P123; (2) 60 partitions (three codon positions for each of the 13 PCGs, 19 tRNA and two rRNA partitions) for P123R; (3) 26 partitions (two codon positions for each of the 13 PCGs) for P12; and (4) 47 partitions (two codon positions for each of the 13 PCGs, 19 tRNA and two rRNA partitions) for P123R. The best-fit partitioning schemes and models for ML and BI analyses of four datasets are obtained from the "greedy" algorithm calculated with "unlinked" branch lengths and the Bayesian information criterion (BIC) $[85,86]$ (Table S6).

We performed Bayesian inference (BI) and maximum likelihood (ML) using the best-fit partitioning schemes recommended by PartitionFinder v1.1.1 (Table S6). MrBayes 3.2.2 was used to conduct Bayesian analysis [87]. Two simultaneous runs of two million generations each were conducted for each dataset, each run with one cold and three heated chains. Samples were drawn every 1,000 Markov chain Monte Carlo (MCMC) steps, with the first 25\% discarded as burn-in. When the average standard deviation of split frequencies was below 0.01 , we considered the stationarity as having been reached for that run. For ML analysis was performed by RAxML 8.0.0 [88] with 100 runs for searching an optimal tree and another 500 pseudo-replicates for the bootstrap analyses (random seed value 12345). Bootstrap values were mapped onto the optimal tree after searching using Sumtrees Version 4.0.0 [89].

Supplementary Materials: Supplementary materials can be found at www.mdpi.com/1422-0067/18/4/773/s1.

Acknowledgments: We express our sincere thanks to Jinying Yang for identification of the specimens of Celyphidae. Thanks to Hu Li (CAU) and Andreas Zwick (ANIC) for giving suggestions in phylogenetic analysis. Ding Yang was funded by the National Natural Science Foundation of China (31320103902 and 31272354). Wenliang Li was funded by the National Natural Science Foundation of China (31301903). Li Shi was funded by the National Natural Science Foundation of China, Beijing (31660622); and the Outstanding Youth Cultivation Fund of Inner Mongolia, Hohhot, Nei Mongol (2015JQ03). Stephen L. Cameron was funded by the Australian Research Council (FT120100746).

Author Contributions: Conceived and designed the experiments: Ding Yang, Li Shi. Performed the experiments: Xuankun Li, Shuangmei Ding. Analyzed the data: Xuankun Li, Shuangmei Ding, Wenliang Li. Contributed reagents/materials/analysis tools: Wenliang Li, Li Shi. Wrote the paper: Xuankun Li, Stephen L. Cameron, Meng Mao.

Conflicts of Interest: The authors declare no conflict of interest.

\section{References}

1. Koehler, C.M.; Bauer, M.F. Mitochondrial Function and Biogenesis; Springer: Berlin, Germany, $2004 ;$ p. 341. 
2. Cameron, S.L. Insect mitochondrial genomics: Implications for evolution and phylogeny. Annu. Rev. Entomol. 2014, 59, 95-117. [CrossRef] [PubMed]

3. Cameron, S.L. How to sequence and annotate insect mitochondrial genomes for systematic and comparative genomics research. Syst. Entomol. 2014, 39, 400-411. [CrossRef]

4. Simon, C.; Frati, F.; Beckenbach, A.; Crespi, B.; Liu, H.; Flook, P. Evolution, weighting, and phylogenetic utility of mitochondrial gene-sequences and a compilation of conserved polymerase chain-reaction primers. Ann. Entomol. Soc. Am. 1994, 87, 651-701. [CrossRef]

5. Cameron, S.L.; Sullivan, J.; Song, H.; Miller, K.B.; Whiting, M.F. A mitochondrial genome phylogeny of the Neuropterida (lace-wings, alderlies and snakelies) and their relationship to the other holometabolous insect orders. Zool. Scr. 2009, 38, 575-590. [CrossRef]

6. Nelson, L.A.; Lambkin, C.L.; Batterham, P.; Wallman, J.F.; Dowton, M.; Whiting, M.F.; Yeates, D.K.; Cameron, S.L. Beyond barcoding: A mitochondrial genomics approach to molecular phylogenetics and diagnostics of blowflies (Diptera: Calliphoridae). Gene 2012, 511, 131-142. [CrossRef] [PubMed]

7. Zhao, Z.; Su, T.; Chesters, D.; Wang, S.; Ho, S.Y.W.; Zhu, C.; Chen, X. The mitochondrial genome of Elodia flavipalpis Aldrich (Diptera: Tachinidae) and the evolutionary timescale of tachinid flies. PLoS ONE 2013, 8, e61814. [CrossRef] [PubMed]

8. Ma, C.; Yang, P.; Jiang, F.; Chapuis, M.; Shali, Y.; Sword, G.A.; Kang, L. Mitochondrial genomes reveal the global phylogeography and dispersal routes of the migratory locust. Mol. Ecol. 2012, 21, 4344-4358. [CrossRef] [PubMed]

9. Logue, K.; Chan, E.R.; Phipps, T.; Small, S.; Reimer, L.; Henry-Halldi, C.; Sattabongkot, J.; Siba, P.M.; Zimmerman, P.A.; Serre, D. Mitochondrial genome sequences reveal deep divergences among Anopheles punctulatus sibling species in Papua New Guinea. Malar J. 2013, 12, 64. [CrossRef] [PubMed]

10. Clary, D.O.; Wolstenholme, D.R. The mitochondrial DNA molecule of Drosophila yakuba: Nucleotide sequence, gene organization, and genetic code. J. Mol. Evol. 1985, 22, 252-271. [CrossRef] [PubMed]

11. Beckenbach, T.A. Mitochondrial genome sequences of Nematocera (Lower Diptera): Evidence of rearrangement following a complete genome duplication in a winter crane fly. Genome Biol. Evol. 2012, 4, 89-101. [CrossRef] [PubMed]

12. Cameron, S.L.; Lambkin, C.L.; Barker, S.C.; Whiting, M.F. A mitochondrial genome phylogeny of Diptera: Whole genome sequence data accurately resolve relationships over broad timescales with high precision. Syst. Entomol. 2007, 32, 40-59. [CrossRef]

13. Zhong, M.; Wang, X.; Liu, Q.; Luo, B.; Wu, C.; Wen, J. The complete mitochondrial genome of the scuttle fly, Megaselia scalaris (Diptera: Phoridae). Mitochondr. DNA Part A 2016, 27, 182-184. [CrossRef]

14. Nelson, L.A.; Cameron, S.L.; Yeates, D.K. The complete mitochondrial genome of the gall-forming fly, Fergusonina taylori Nelson and Yeates (Diptera: Fergusoninidae). Mitochondr. DNA 2011, 22, 197-199. [CrossRef]

15. Yang, F.; Du, Y.; Cao, J.; Huang, F. Analysis of three leafminers' complete mitochondrial genomes. Gene 2013, 529, 1-6. [CrossRef] [PubMed]

16. Yang, F.; Du, Y.; Wang, L.; Cao, J.; Yu, W. The complete mitochondrial genome of the leafminer Liriomyza sativae (Diptera: Agromyzidae): Great difference in the A + T-rich region compared to Liriomyza trifolii. Gene 2011, 485, 7-15. [CrossRef] [PubMed]

17. Wang, S.; Lei, Z.; Wang, H.; Dong, B.; Ren, B. The complete mitochondrial genome of the leafminer Liriomyza trifolii (Diptera: Agromyzidae). Mol. Biol. Rep. 2011, 38, 687-692. [CrossRef]

18. Ye, J.; Fang, R.; Yi, J.; Zhou, G.; Zheng, J. The complete sequence determination and analysis of four species of Bactrocera mitochondrial genome. Plant Quarantine 2010, 24, 11-14.

19. Yu, D.J.; Xu, L.; Nardi, F.; Li, J.G.; Zhang, R.J. The complete nucleotide sequence of the mitochondrial genome of the oriental fruit fly, Bactrocera dorsalis (Diptera: Tephritidae). Gene 2007, 396, 66-74. [CrossRef]

20. Zhang, B.; Nardi, F.; Hull-Sanders, H.; Wan, X.; Liu, Y. The complete nucleotide sequence of the mitochondrial genome of Bactrocera minax (Diptera: Tephritidae). PLoS ONE 2014, 9, e100558. [CrossRef] [PubMed]

21. Nardi, F.; Carapelli, A.; Dallai, R.; Frati, F. The mitochondrial genome of the olive fly Bactrocera oleae: Two haplotypes from distant geographical locations. Insect Mol. Biol. 2003, 12, 605-611. [CrossRef]

22. Nardi, F.; Carapelli, A.; Boore, J.L.; Roderick, G.K.; Dallai, R.; Frati, F. Domestication of olive fly through a multi-regional host shift to cultivated olives: Comparative dating using complete mitochondrial genomes. Mol. Phylogenet. Evol. 2010, 57, 678-686. [CrossRef] [PubMed] 
23. Spanos, L.; Koutroumbas, G.; Kotsyfakis, M.; Louis, C. The mitochondrial genome of the Mediterranean fruit fly, Ceratitis capitata. Insect Mol. Biol. 2000, 9, 139-144. [CrossRef] [PubMed]

24. Clark, A.G.; Eisen, M.B.; Smith, D.R.; Bergman, C.M.; Oliver, B.; Markow, T.A.; Kaufman, T.C.; Kellis, M.; Gelbart, W.; Iyer, V.N.; et al. Evolution of genes and genomes on the Drosophila phylogeny. Nature 2007, 450, 203-218. [CrossRef] [PubMed]

25. Andrianov, B.; Goryacheva, I.; Mugue, N.; Sorokina, S.; Gorelova, T.; Mitrfanov, V. Comparative analysis of the mitochondrial genomes in Drosophila virilis species group (Diptera: Drosophilidae). Trends Evol. Biol. 2010, 2, e4. [CrossRef]

26. Lewis, D.L.; Farr, C.L.; Kaguni, L.S. Drosophila melanogaster mitochondrial DNA: Completion of the nucleotide sequence and evolutionary comparisons. Insect Mol. Biol. 1995, 4, 263-278. [CrossRef] [PubMed]

27. Torres, T.T.; Dolezal, M.; Schlötterer, C.; Otenwalder, B. Expression profiling of Drosophila mitochondrial genes via deep mRNA sequencing. Nucleic Acids Res. 2009, 37, 7509-7518. [CrossRef] [PubMed]

28. Llopart, A.; Herrig, D.; Brud, E.; Stecklein, Z. Sequential adaptive introgression of the mitochondrial genome in Drosophila yakuba and Drosophila santomea. Mol. Ecol. 2014, 23, 1124-1136. [CrossRef] [PubMed]

29. Ballard, J.W.O. Comparative genomics of mitochondrial DNA in members of the Drosophila melanogaster subgroup. J. Mol. Evol. 2000, 51, 48-63. [CrossRef] [PubMed]

30. Li, X.; Ding, S.; Cameron, S.L.; Kang, Z.; Wang, Y.; Yang, D. The First Mitochondrial genome of the sepsid fly Nemopoda mamaevi Ozerov, 1997 (Diptera: Sciomyzoidea: Sepsidae), with mitochondrial genome phylogeny of Cyclorrhapha. PLoS ONE 2015, 10, e0123594. [CrossRef] [PubMed]

31. Oliveira, M.T.; Barau, J.G.; Junqueira, A.C.M.; Ferjao, P.C.; da Rosa, A.C.; Abreu, C.F.; Azeredo-Espin, A.M.L. Structure and evolution of the mitochondrial genomes of Haematobia irritans and Stomoxys calcitrans: The Muscidae (Diptera: Calyptratae) perspective. Mol. Phylogenet. Evol. 2008, 48, 850-857. [CrossRef] [PubMed]

32. Li, X.; Wang, Y.Y.; Su, S.; Yang, D. The complete mitochondrial genomes of Musca domestica and Scathophaga stercoraria (Diptera: Muscoidea: Muscidae and Scathophagidae). Mitochondr. DNA Part A 2016, 27, 1435-1436. [CrossRef] [PubMed]

33. Ding, S.; Li, X.; Wang, N.; Cameron, S.L.; Mao, M.; Wang, Y.; Xi, Y.; Yang, D. The phylogeny and evolutionary timescale of muscoidea (Diptera: Brachycera: Calyptratae) inferred from mitochondrial genomes. PLoS ONE 2015, 10, e0134170. [CrossRef] [PubMed]

34. Junqueira, A.C.M.; Lessinger, A.C.; Torres, T.T.; da Silva, F.R.; Vettore, A.L.; Arruda, P.; Espin, A.M.L. The mitochondrial genome of the blowfly Chrysomya chloropyga (Diptera: Calliphoridae). Gene 2004, 339, 7-15. [CrossRef] [PubMed]

35. Lessinger, A.C.; Martins Junqueira, A.C.; Lemos, T.A.; Kemper, E.L.; da Silva, F.R.; Vettore, A.L.; Arruda, P.; Azeredo-Espin, A.M.L. The mitochondrial genome of the primary screwworm fly Cochliomyia hominivorax (Diptera: Calliphoridae). Insect Mol. Biol. 2000, 9, 521-529. [CrossRef] [PubMed]

36. De Azeredo-Espin, A.M.L. The complete mitochondrial genome of the human bot fly Dermatobia hominis (Diptera: Oestridae). In Proceedings of the 2004 ESA Annual Meeting and Exhibition, Salt Lake City, UT, USA, 14-17 November 2004.

37. Weigl, S.; Testini, G.; Parisi, A.; Dantas-Torres, F.; Traversa, D.; Colwell, D.D.; Otranto, D. The mitochondrial genome of the common cattle grub, Hypoderma lineatum. Med. Vet. Entomol. 2010, 24, 329-335. [CrossRef] [PubMed]

38. Zhong, M.; Wang, X.; Liu, Q.; Luo, B.; Wu, C.; Wen, J. The complete mitochondrial genome of the flesh fly, Boettcherisca peregrine (Diptera: Sarcophagidae). Mitochondr. DNA Part A 2016, 27, 106-108. [CrossRef] [PubMed]

39. Shao, Y.; Hu, X.; Wang, R.; Gao, R.; Lin, C.; Shen, W.; Li, R.; Li, B. Structure and evolution of the mitochondrial genome of Exorista sorbillans: The Tachinidae (Diptera: Calyptratae) perspective. Mol. Biol. Rep. 2012, 39, 11023-11030. [CrossRef] [PubMed]

40. Hendel, F. Beitrage zur Systematik der Acalyptraten Musciden. Ent. Mitt. 1916, 5, 294-299.

41. Hendel, F. Die palaarktischen Muscidae Acalyptrate Girsch. = Haplostomata Frey nach ihre Familien und Gattungen I. Die Familien. Konowia 1922, 1, 145-160.

42. Hennig, W. Die Familien der Diptera Schizophora und ihre phylogenetischen Verwandtschaftsbeziehungen. Entomol. Beitr. 1958, 8, 505-688.

43. Hennig, W. Neue Untersuchungen über die Familien der Diptera Schizophora (Diptera: Cyclorrhapha). Stuttg. Beitr. Naturk. 1971, 226, 1-76. (In German) 
44. Hennig, W. Diptera (Zweiflügler). Handbuch der Zoologie 1973, 4, 1-200.

45. Gaimari, S.D.; Silva, V.C. Revision of the Neotropical subfamily Eurychoromyiinae (Diptera: Lauxaniidae). Zootaxa 2010, 2342, 1-64.

46. Reddersen, J. Distribution and abundance of lauxaniid flies in Danish cereal fields in relation to pesticides, crop and field boundary (Diptera, Lauxaniidae). Entomol. Medd. 1994, 62, 117-128.

47. Marshall, S.A. Flies: The Natural History \& Diversity of Diptera; Firefly Books: Richmond Hill, ON, Canada, 2012; p. 616.

48. Yeates, D.K.; Wiegmann, B.M.; Courtney, G.W.; Meier, R.; Lambkin, C.; Pape, T. Phylogeny and systematics of Diptera: Two decades of progress and prospects. Zootaxa 2007, 1688, 565-590.

49. McAlpine, J.F. Phylogeny and classification of the Muscomorpha. In Manual of Nearctic Diptera; McAlpine, J.F., Wood, D.M., Eds.; Research Branch Agriculture Canada: Ottawa, ON, Canada, 1989; Volume 3, pp. 1397-1518.

50. Griffiths, G.C. The Phylogenetic Classification of Diptera Cyclorrhapha, with Special Reference to the Structure of the Male Postabdomen; Springer: The Hague, The Netherlands, 1972; p. 339.

51. Wiegmann, B.M.; Trautwein, M.D.; Winkler, I.S.; Barr, N.B.; Kim, J.; Lambkin, C.; Bertone, M.A.; Cassel, B.K.; Bayless, K.M.; Heimberg, A.M.; et al. Episodic radiations in the fly tree of life. Proc. Natl. Acad. Sci. USA 2011, 108, 5690-5695. [CrossRef] [PubMed]

52. Hennig, W. Die Acalyptratae des Baltischer Bernsteins. Stuttg. Beitr. Naturk. 1965, 145, 1-215.

53. Lambkin, C.L.; Sinclair, B.J.; Pape, T.; Courtney, G.W.; Skevington, J.H.; Meier, R.; Yeates, D.K.; Blagoderov, V.; Wiegmann, B.M. The phylogenetic relationships among infraorders and superfamilies of Diptera based on morphological evidence. Syst. Entomol. 2013, 38, 164-179. [CrossRef]

54. Zhu, Z.; Liao, H.; Ling, J.; Cai, J.; Ding, Y. The complete mitochondria genome of Aldrichina grahami (Diptera: Calliphoridae). Mitochondr. DNA Part B 2016, 1, 107-109. [CrossRef]

55. Grant, J.R.; Stothard, P. The CGView Server: A comparative genomics tool for circular genomes. Nucleic Acids Res. 2008, 36, W181-W184. [CrossRef] [PubMed]

56. Wei, S.; Shi, M.; Chen, X.; Sharkey, M.J.; van Achterberg, C.; Ye, G.; He, J. New views on strand asymmetry in insect mitochondrial genomes. PLoS ONE 2010, 5, e12708. [CrossRef] [PubMed]

57. Cameron, S.L.; Lo, N.; Bourguignon, T.; Svenson, G.J.; Evans, T.A. A mitochondrial genome phylogeny of termites (Blattodea: Termitoidae): Robust support for interfamilial relationships and molecular synapomorphies define major clades. Mol. Phylogenet. Evol. 2012, 65, 163-173. [CrossRef] [PubMed]

58. Roberti, M.; Polosa, P.L.; Bruni, F.; Musicco, C.; Gadaleta, M.N.; Cantatore, P. DmTTF, a novel mitochondrial transcription termination factor that recognizes two sequences of Drosophila melanogaster mitochondrial DNA. Nucleic Acids Res. 2003, 31, 1597-1604. [CrossRef] [PubMed]

59. Taanman, J.W. Themitochondrial genome: Structure, transcription, translation and replication. Biochim. Biophys. Acta 1999, 1410, 103-123. [CrossRef]

60. Wolstenholme, D.R. Animal mitochondrial DNA: Structure and evolution. Int. Rev. Cytol. 1992, 141, $173-216$. [PubMed]

61. Lavrov, D.V.; Brown, W.M.; Boore, J.L. A novel type of RNA editing occurs in the mitochondrial tRNAs of the centipede Lithobius forficatus. Proc. Natl. Acad. Sci. USA 2000, 97, 13738-13742. [CrossRef] [PubMed]

62. Cannone, J.J.; Subramanian, S.; Schnare, M.N.; Collett, J.R.; D’Souza, L.M.; Du, Y.; Feng, B.; Lin, N.; Madabusi, L.V.; Muller, K.M. The Comparative RNA Web (CRW) Site: An online database of comparative sequence and structure information for ribosomal, intron, and other RNAs. BMC Bioinform. 2002, 3, 1-31.

63. Abascal, F.; Posada, D.; Zardoya, R. The evolution of the mitochondrial genetic code in arthropods revisited. Mitochondr. DNA 2012, 23, 84-91. [CrossRef] [PubMed]

64. Abascal, F.; Posada, D.; Knight, R.D.; Zardoya, R. Parallel evolution of the genetic code in arthropod mitochondrial genomes. PLoS Biol. 2006, 4, 711-718. [CrossRef] [PubMed]

65. Knight, R.D.; Freeland, S.J.; Landweber, L.F. Rewiring the keyboard: Evolvability of the genetic code. Nat. Rev. Genet. 2001, 2, 49-58. [CrossRef] [PubMed]

66. Rawlings, T.A.; Collins, T.M.; Bieler, R. Changing identities: tRNA duplication and remolding within animal mitochondrial genomes. Proc. Natl. Acad. Sci. USA 2003, 100, 15700-15705. [CrossRef]

67. Sengupta, S.; Yang, X.G.; Higgs, P.G. The mechanisms of codon reassignments in mitochondrial genetic codes. J. Mol. Evol. 2007, 64, 662-688. [CrossRef] [PubMed] 
68. Wang, Y.; Li, H.; Wang, P.; Song, F.; Cai, W. Comparative Mitogenomics of Plant Bugs (Hemiptera: Miridae): Identifying the AGG Codon Reassignments between Serine and Lysine. PLoS ONE 2014, 9, e101375. [CrossRef] [PubMed]

69. Boore, J.L. Requirements and standards for organelle genome databases. OMICS 2006, 10, 119-126. [CrossRef] [PubMed]

70. Griffiths, G. Book review: Manual of Nearctic Diptera, Vol. 3. Quaest. Entomol. 1990, 26, 117-130.

71. Cumming, J.M.; Sinclair, B.J.; Wood, D.M. Homology and phylogenetic implications of male genitalia in Diptera-Eremoneura. Entomol. Scand. 1995, 26, 121-151. [CrossRef]

72. Wada, S. Morphologische Indizien für das unmittelbare Schwestergruppenverhältnis der Schizophora mit den Syrphoidea ('Aschiza') in der phylogenetischen Systematik der Cyclorrhapha (Diptera: Brachycera). J. Nat. Hist. 1991, 25, 1531-1570. (In German) [CrossRef]

73. Zatwarnicki, T. A new reconstruction of the origin of the eremoneuran hypopygium and its implications for classification (Insecta: Diptera). Genus 1996, 3, 103-175.

74. Wang, K.; Li, X.; Ding, S.; Wang, N.; Mao, M.; Wang, M.; Yang, D. The complete mitochondrial genome of the Atylotus miser (Diptera: Tabanomorpha: Tabanidae), with mitochondrial genome phylogeny of lower Brachycera (Orthorrhapha). Gene 2016, 586, 184-196. [CrossRef] [PubMed]

75. Hall, T.A. BioEdit: A user-friendly biological sequence alignment editor and analysis program for Windows 95/98/NT. Nucleic Acids Symp. Ser. 1999, 41, 95-98.

76. Lowe, T.M.; Eddy, S.R. tRNAscan-SE: A program for improved detection of transfer RNA genes in genomic sequence. Nucleic Acids Res. 1997, 25, 0955-0964. [CrossRef]

77. Tamura, K.; Peterson, D.; Peterson, N.; Stecher, G.; Nei, M.; Kumar, S. MEGA5: Molecular evolutionary genetics analysis using maximum likelihood, evolutionary distance, and maximum parsimony methods. Mol. Biol. Evol. 2011, 28, 2731-2739. [CrossRef] [PubMed]

78. Perna, N.T.; Kocher, T.D. Patterns of nucleotide composition at fourfold degenerate sites of animal mitochondrial genomes. J. Mol. Evol. 1995, 41, 353-358. [CrossRef] [PubMed]

79. Abascal, F.; Zardoya, R.; Telford, M.J. TranslatorX: Multiple alignment of nucleotide sequences guided by amino acid translations. Nucleic Acids Res. 2010, 38, W7-W13. [CrossRef] [PubMed]

80. Castresana, J. Selection of conserved blocks from multiple alignments for their use in phylogenetic analysis. Mol. Biol. Evol. 2000, 17, 540-552. [CrossRef] [PubMed]

81. Tabei, Y.; Kiryu, H.; Kin, T.; Asai, K. A fast structural multiple alignment method for long RNA sequences. BMC Bioinform. 2008, 9, 33. [CrossRef] [PubMed]

82. Edgar, R.C. MUSCLE: Multiple sequence alignment with high accuracy and high throughput. Nucleic Acids Res. 2004, 32, 1792-1797. [CrossRef] [PubMed]

83. Vaidya, G.; Lohman, D.J.; Meier, R. SequenceMatrix: Concatenation software for the fast assembly of multi-gene datasets with character set and codon information. Cladistics 2010, 27, 171-180. [CrossRef]

84. Lanfear, R.; Calcott, B.; Ho, S.Y.W.; Guindon, S. PartitionFinder: Combined selection of partitioning schemes and substitution models for phylogenetic analysis. Mol. Biol. Evol. 2012, 29, 1695-1701. [CrossRef] [PubMed]

85. Miller, K.B.; Bergsten, J.; Whiting, M.F. Phylogeny and classification of the tribe Hydaticini (Coleoptera: Dytiscidae): Partition choice for Bayesian analysis with multiple nuclear and mitochondrial protein-coding genes. Zool. Scr. 2009, 38, 591-615. [CrossRef]

86. Pons, J.; Ribera, I.; Bertranpetit, J.; Balke, M. Nucleotide substitution rates for the full set of mitochondrial protein-coding genes in Coleoptera. Mol. Phylogenet. Evol. 2010, 56, 796-807. [CrossRef] [PubMed]

87. Ronquist, F.; Huelsenbeck, J.P. MrBayes 3: Bayesian phylogenetic inference under mixed models. Bioinformatics 2003, 19, 1572-1574. [CrossRef] [PubMed]

88. Stamatakis, A. RAxML-VI-HPC: Maximum likelihood-based phylogenetic analysis with thousands of taxa and mixed models. Bioinformatics 2006, 22, 2688-2690. [CrossRef] [PubMed]

89. Sukumaran, J.; Holder, M.T. SumTrees: Phylogenetic Tree Summarization. 4.0.0. Available online: https: / / github.com/jeetsukumaran/DendroPy (accessed on 3 April 2017).

(C) 2017 by the authors. Licensee MDPI, Basel, Switzerland. This article is an open access article distributed under the terms and conditions of the Creative Commons Attribution (CC BY) license (http:/ / creativecommons.org/licenses/by/4.0/). 